\title{
Experimental study of the oxidation of large surrogates for diesel and biodiesel fuels
}

\author{
Mohammed Hichem Hakka ${ }^{a}$, Pierre-Alexandre Glaude ${ }^{a}$, Olivier Herbinet ${ }^{a, *}$ and Frédérique \\ Battin-Leclerc $^{a}$
}

\footnotetext{
a Département de Chimie Physique des Réaction, Nancy Université, CNRS, Ecole Nationale Supérieure des Industries Chimiques (ENSIC), BP 20451, 1 rue Grandville, 54001 Nancy, France
}

\begin{abstract}
The experimental study of the oxidation of two blend surrogates for diesel and biodiesel fuels, $\mathrm{n}$-decane/n-hexadecane and $\mathrm{n}$-decane/methyl palmitate $(74 / 26 \mathrm{~mol} / \mathrm{mol})$, has been performed in a jet-stirred reactor over a wide range of temperatures covering both low, and high-temperature regions (550-1100 K), at a residence time of $1.5 \mathrm{~s}$, at quasi atmospheric pressure with high dilution in helium (hydrocarbon inlet mole fraction of 0.002 ) and at stoichiometric conditions.

Numerous reaction products have been identified and quantified. At low and intermediate temperatures (less than $1000 \mathrm{~K}$ ), the formation of oxygenated species such as cyclic ethers, aldehydes and ketones has been observed for $\mathrm{n}$-decane, $\mathrm{n}$-hexadecane, and methyl palmitate. At higher temperature, the formation of these species was not observed any more, and small amounts of unsaturated species (olefins and unsaturated methyl esters) have been detected.

Results obtained with methyl palmitate and $\mathrm{n}$-hexadecane have been compared in order to highlight similarities and differences between large $n$-alkanes and methyl esters.
\end{abstract}

Keywords: Oxidation; Diesel; Biodiesel; Methyl esters; n-Decane; n-Hexadecane; Methyl palmitate; Jet-stirred reactor; Engine

Corresponding author: Olivier Herbinet Laboratoire Réactions et Génie des Procédés, CNRS UPR 3349, Nancy-Université, ENSIC, 1 rue Grandville, BP 20451, 54001 Nancy Cedex, France.

Tel : +33 383175360 ; Fax : +33 383378120

E-mail : olivier.herbinet@ensic.inpl-nancy.fr 


\section{Introduction}

Biodiesels are new alternative renewable fuels that could answer some of the energy issues that the world is currently facing [1] and [2]. They are new potential sources of energy that can help to reduce the dependence on petroleum, and it has been demonstrated that their use in diesel engines allows decreasing the amount of some pollutants (carbon monoxide, soot) formed during the combustion. Nitrogen oxide emissions seem to be slightly higher under some engine conditions [3] and [4].

Biodiesels are composed of fatty acid esters obtained from vegetable oils and animal fats through a process of trans-esterification with an alcohol (e.g., methanol and ethanol) [1]. Biodiesels are mainly produced from rapeseed oil in European countries and from soybean oil in the United States. When methanol is used, they contain five main esters: methyl palmitate, methyl stearate, methyl oleate, methyl linoleate, and methyl linolenate. The structures of these molecules and the average composition [5] of rapeseed and soybean biodiesels are shown in Table 1. All these esters have very similar structures: a long alkyl chain attached to a methyl ester group. Differences are the length of the alkyl chain (15 atoms of carbon for methyl palmitate and 17 atoms of carbon for the other esters) and the number of double bonds in the chain (no double bond for methyl palmitate and methyl stearate, one double bond for methyl oleate, two double bonds for methyl linoleate and three double bonds for methyl linolenate).

Table 1. Structures of methyl esters and average composition in rapeseed and soybean biodiesels [5].

methyl linoleate $\left(\mathrm{C}_{19} \mathrm{H}_{32} \mathrm{O}_{2}\right)$

In contrast to n-alkanes [6], [7], [8], [9] and [10], experimental studies of the combustion of biodiesel fuels or of their individual components are still very scarce. Methyl butanoate $\left(\mathrm{C}_{5} \mathrm{H}_{10} \mathrm{O}_{2}\right)$ combustion 
has been the subject of several studies in the past years because it has a much shorter alkylic chain than esters present in real biodiesels (its vapor pressure is much higher, making gas phase kinetic studies easier). These studies led to a better understanding of the specific chemistry, due to the presence of the ester group, but they also demonstrated that methyl butanoate is not a good surrogate for biodiesels because the alkylic chain is too short and the influence of the ester group on the chemistry is emphasized. In the 1950s the combustion of methyl butanoate was studied in closed vessels [11]. Pressure data were recorded as a function of time. These experimental results were used by Fisher et al. in the validation of a detailed kinetic mechanism for the oxidation of this species [12]. While the experimental studies have mainly been performed under conditions corresponding to the high-temperature region, this mechanism, written by analogy with n-alkanes, included all relevant pathways for both low- and high-temperature regions. Metcalfe et al. [13] measured ignition delay times for methyl butanoate and ethyl propanoate in a shock tube over the temperature range $1100-1670 \mathrm{~K}$ and at pressures of 1.0 and $4.0 \mathrm{~atm}$. They proposed a new version of the methyl butanoate mechanism based on that developed by Fisher et al. [12]. Gaïl et al. [14] studied the oxidation of methyl butanoate in three different apparatuses. Experiments were performed in a jet-stirred reactor (atmospheric pressure, dilute conditions, temperature range 800$1350 \mathrm{~K}$, equivalence ratio $\phi 1.13$, residence time $\tau 0.07 \mathrm{~s})$, in a variable pressure flow reactor $(P=$ $1.266 \mathrm{MPa}$, dilute conditions, $\phi=0.35$ and $1.00, \tau=1.8 \mathrm{~s}$ ), and in an opposed-flow diffusion flame. Reaction products were sampled at the outlet of the jet-stirred and flow reactors and withdrawn with a quartz micro-probe within the opposed flow diffusion flame. Species were analyzed by gas chromatography (flame ionization detector) and FTIR. Mole fraction profiles were plotted for the reactants (methyl butanoate and oxygen) and for numerous reaction products. Gail et al. also proposed a new version of the Fischer et al. [12] mechanism with validation using their experimental data. In a more recent paper, Gail et al. [15] studied the oxidation of methyl butanoate and methyl crotonate $\left(\mathrm{C}_{5} \mathrm{H}_{8} \mathrm{O}_{2}\right)$, an ester with one double bond conjugated with the carbonyl group, in a jetstirred reactor (atmospheric pressure, large dilution, temperature range 850-1400 K, two equivalence ratios $\phi=0.375$ and 0.7 , residence time $0.07 \mathrm{~s}$ ) and in an opposed-flow diffusion flame. Mole fraction profiles were plotted for the reactants and for several reaction products. This comparison study showed that the formation of unsaturated species was enhanced in the case of methyl crotonate. A model of the oxidation of these species has been developed from mechanisms previously published in the literature. A kinetic analysis of this mechanism showed that the reactions pathways are very similar for both molecules and highlighted the role of the ester function and of the double bond in the unsaturated ester. Farooq et al. [16] studied the high-temperature decomposition of three esters (methyl acetate, methyl propionate and methyl butanoate) in a shock tube (temperature range 1260-1653 K, pressures 1.4-1.7 atm and reactant concentrations $2-3 \%$, in argon). $\mathrm{CO} 2$ yield measurements were performed using a laser based method and compared to yields calculated from several mechanisms. The auto-ignition of methyl butanoate in a rapid compression machine was studied by Walton et al. [17] (experiments at $\mathrm{T}=935-1117 \mathrm{~K}, \mathrm{P}=4.7-19.6$ atm, and $\phi=0.3-0.4$.) and ignition delay times were compared to a new model derived from that of Metcalfe et al. [13]. Dooley et al. [18] studied the auto-ignition of methyl butanoate in a shock tube (at 1 and $4 \mathrm{~atm}$, over the temperature range 1250-1760 $\mathrm{K}$, at $\phi=1.5,1.0,0.5$, and 0.25 , and at fuel concentrations $1.0 \%$ and $1.5 \%$ ) and in a rapid compression machine (temperature range $640-949 \mathrm{~K}$ at compressed gas pressures of 10,20, and $40 \mathrm{~atm}, \phi$ of $1.0,0.5$, and 0.33 , and fuel concentrations of $1.59 \%$ and $3.13 \%$. These new experimental results and other data from the literature were used to produce a model of the oxidation of methyl butanoate. Vaughn et al. [19] measured droplet ignition 
delay times for several methyl esters and real biodiesels. This study provided interesting results, since they demonstrated that large methyl esters such as methyl decanoate $\left(\mathrm{C}_{11} \mathrm{H}_{22} \mathrm{O}_{2}\right)$, methyl dodecanoate $\left(\mathrm{C}_{13} \mathrm{H}_{26} \mathrm{O}_{2}\right)$, methyl oleate, and soybean biodiesel have very close reactivities, whereas ignition delay times for methyl butanoate are much longer. This confirms that methyl butanoate is not a good surrogate for biodiesel fuels.

Experimental studies of the oxidation of methyl esters larger than methyl butanoate are very scarce. HadjAli et al. [20] studied the low-temperature auto-ignition of a series of methyl esters from methyl butanoate to methyl heptanoate in a rapid compression machine. Experiments were performed over the temperature range $650-850 \mathrm{~K}$ and at pressures from 4 to 20 bar. They observed that the reactivity of the ester increased with the number of carbon atoms in the alkyl chain as for the $\mathrm{n}$-alkanes. Ignition delay times of methyl hexanoate were compared with ignition delay times of a series of $n$-alkanes (n-butane, $n$-pentane, and $n$-heptane). This comparative study showed that the first stage delay times of methyl hexanoate were very close to those of $n$-heptane. The delay times at temperatures less than $670 \mathrm{~K}$ were also very close to those of $\mathrm{n}$-heptane, but a major difference was the position of the negative-temperature-coefficient region, which occurred at lower temperature in the case of methyl hexanoate. Dagaut et al. [21] performed the study of the oxidation of rapeseed oil methyl ester (RME) in a jet-stirred reactor working at pressures between 1 and $10 \mathrm{~atm}$, at temperatures from 800 to $1400 \mathrm{~K}$, at high dilution in helium, and at two equivalence ratios ( 0.5 and 1 ). The formation of numerous reaction products has been observed. These products are carbon oxides, hydrogen, methane, ethylene, and larger olefins from propene to 1-hexene. The formation of unsaturated esters is not reported in this paper, whereas Dagaut and Gaïl [22] observed this type of species (methyl esters with one double bond at the extremity of the alkyl chain) when studying the oxidation of a blend of Jet-A1 and RME in a jet-stirred reactor. The formation of these species is expected because they can be formed by the same pathways as those leading to olefins during the oxidation of alkanes. Dagaut et al. [21] used a detailed kinetic model for the oxidation of $n$ hexadecane from [23] to reproduce the RME experimental data. The agreement was good for most species, except for the early production of carbon dioxide due to the presence of the ester group in RME. The formation of unsaturated esters has also been observed by Pedersen et al. [24] during the study of the oxidation of RME in a stainless steel tubular reactor at $823 \mathrm{~K}$. More recently, Szybist et al. [25] and [26] used methyl decanoate to fuel a CFR engine with an adjustable compression ratio. Pressure histories have been recorded and numerous products of the reaction have been detected by FTIR analysis and GC-MS. They could observe the formation of carbon oxides, formaldehyde, acetaldehyde, saturated and unsaturated methyl esters, esters with a carbonyl group, carboxylic acids, and more complex oxygenated species. Herbinet et al. [27] developed a model for the oxidation of methyl decanoate including all reactions pertinent to low- and high-temperature regions. The model has been validated against limited available data. One feature of this model is its ability to reproduce the early production of carbon monoxide observed at low temperature by Dagaut et al. [21] during the experiments. The model predicts ignition delay times very close to those observed for $n$-decane in a shock tube and suggests that large methyl esters and alkanes of similar size have very similar reactivities. This large model has been reduced and used to model extinction and ignition of laminar nonpremixed flames containing methyl decanoate [28]. 
Since data about the combustion of model molecules representative of large methyl esters are very scarce, new reliable experimental data are needed to draw comparisons for the reactivity and the formation of oxidation products between large $n$-alkanes and methyl esters and to validate detailed kinetic models. The goal of this paper is to present new experimental results for the combustion of two surrogate blends for diesel and biodiesel fuels. One surrogate is composed of two large $\mathrm{n}$-alkanes, $\mathrm{n}$-decane and $\mathrm{n}$-hexadecane, and the other one is a blend of $\mathrm{n}$-decane and methyl palmitate $(74 / 26 \mathrm{~mol} / \mathrm{mol})$. Methyl palmitate has been chosen because it is present in real biodiesel fuels (Table 1) and because it is representative of other large saturated esters. $n$-Hexadecane has been used because it is a reference molecule for the calculation of the cetane number ( $n$-hexadecane is assigned a cetane number of 100) and because this n-alkane contains as many carbon atoms as the alkyl chain in methyl palmitate (16 carbon atoms). The study of the oxidation of these surrogates has been performed in a jet-stirred reactor under similar conditions to make a direct comparison (equivalence ratio and mole fraction of oxygen held constant and hydrocarbon mole fraction adjusted to maintain constant the concentration of carbon atoms at the inlet of the reactor). This paper focuses on the identification of the reaction products because for some species (e.g., cyclic ethers formed at low temperature and unsaturated esters) pure substances were not available for retention time calibration and mass spectra were not in the databases. Similarities and differences between large $n$-alkanes and methyl esters are then discussed.

\section{Experimental methods}

The experimental study of the oxidation of large $n$-alkanes and methyl esters has been performed with an apparatus which has already been used in our laboratory for studies of the thermal decomposition and the oxidation of organic compounds [7] and [29]. Only the main features of this apparatus are presented here.

\subsection{Experimental apparatus specifications}

Experiments have been performed in a spherical quartz jet-stirred reactor operated at constant temperature and pressure. This is a type of reactor which is well adapted for kinetic studies because the gas phase inside the reactor is well stirred and concentrations are homogenous therein [30] and [31]. The stirring is achieved by turbulent jets flowing through an injection cross located at the center of the sphere. The internal volume of the reactor is $92 \mathrm{~cm}^{3}$ and it has been designed to be well stirred for residence times between 0.5 and $5 \mathrm{~s}$. It is preceded by an annular preheater to avoid gradients of temperature therein. The residence time of the gas inside the preheater is $1 \%$ of the total residence time in the reactor. The heating is achieved with independent thermocoax resistance coiled around the different zones. 
Studies of the oxidation of $\mathrm{n}$-decane, $\mathrm{n}$-decane/n-hexadecane, and $\mathrm{n}$-decane/methyl palmitate have been performed at temperatures ranging from 550 to $1100 \mathrm{~K}$, at a residence time of $1.5 \mathrm{~s}$ and at a pressure of $106 \mathrm{kPa}$. Reactants were diluted in helium. The inlet mole fraction of hydrocarbon was 0.0023 for the study of the oxidation of pure $n$-decane and was 0.002 for both blends (composed of $74 \mathrm{~mol} \%$ of $n$-decane and $26 \mathrm{~mol} \%$ of $n$-hexadecane or methyl palmitate).

\subsection{Products analyses}

Reaction products were analyzed by gas chromatography. Analyses were performed in three steps due to the formation of compounds which were either liquid or gaseous under standard conditions.

For the analysis of the heaviest species (including more than five carbon or oxygen atoms), a trap maintained at liquid nitrogen temperature was connected to the outlet of the reactor. After a given period of time, the trap was disconnected and acetone (solvent) and a known amount of n-octane acting as internal standard were added. When the temperature of the trap was close to room temperature, the liquid mixture in the trap was poured into a sampling bottle and then injected in a Agilent 6850 gas chromatograph. This apparatus was fitted with an automatic sampler, a HP-1 capillary column, and a flame ionization detector (FID). Carrier gas (helium) flow rate was held constant $\left(1 \mathrm{ml} \mathrm{min}^{-1}\right)$ and the temperature profile of the oven was $15 \mathrm{~min}$ at $45^{\circ} \mathrm{C}, 5^{\circ} \mathrm{C} \mathrm{min}{ }^{-1}, 10 \mathrm{~min}$ at $200^{\circ} \mathrm{C}$.

Light species such as oxygen, carbon monoxide, carbon dioxide and $C_{1}-C_{2}$ hydrocarbons were analyzed online by gas chromatography. The gas chromatograph was fitted with a sampling valve, a carbosphere packed column, and two detectors: a thermal conductivity detector (TCD) for oxygen containing species and a FID for hydrocarbons. Helium was used as a carrier gas because it was used as a carrier gas in the experiments. The use of helium was beneficial for the quantification of oxygen (very high sensitivity), but not for hydrogen, which was not quantified. For other light species, samples were taken from the gaseous mixture at the outlet from the reactor and were injected in to a gas chromatograph fitted with a Haysep Packed column and a FID. Nitrogen was used as a carrier gas. Formaldehyde and water were not quantified. The limit of detection for the FID was about 0.1 ppm whatever the hydrocarbon species. For the TCD, the limit of detection mainly depended on the thermal conductivities of the carrier gas and of the solutes. The limit of detection was about $10 \mathrm{ppm}$ for $\mathrm{CO}$ and only $100 \mathrm{ppm}$ for $\mathrm{CO}_{2}$ (the base line was distorted in this region of the chromatograph because of the presence of water). Estimated uncertainties on the species quantifications were about $\pm 5 \%$ with the online analysis of oxygen and $C_{1}-C_{2}$ hydrocarbons and about $\pm 10 \%$ for the analysis of other species. 


\subsection{Identification and calibration of the products}

Identification and calibration of gaseous species were performed by injecting standard gaseous mixtures provided by Air Liquide and Messer.

For heavy products, identification was performed by comparison of retention times of pure substances injected in to gas chromatographs, when they were available. Calibration was performed by plotting peak areas versus masses of the substances injected in to the gas chromatograph compared to those of the internal standard ( $\mathrm{n}$-octane).

Identification of species was also performed with a gas chromatograph coupled with a mass spectrometer. The gas chromatograph was fitted with the same column as the Agilent 6850 gas chromatograph that we used for the quantification of the heavy products, allowing a direct comparison of the two chromatograms. The mass spectra of most reaction products were included in the spectra database "NBS75 K". For other products, which were not in the database, the deciphering of the mass spectra has been carried out. These products were cyclic ethers formed at low temperature and unsaturated esters formed at high temperature during the oxidation of the n-decane/methyl palmitate blend.

The quantification of the species that were not available for calibration has been performed by using the effective carbon method. This method is based on the response of the detector (FID) as a function of the structure of the molecule [32]. For example, the same response is assumed for two species having the same number of carbon atoms and the same type of functional groups (e.g., 1-decene, 2-decene (E), 2-decene (Z)). As a second example, the response of $\mathrm{C}_{10}$ cyclic ethers $\left(\mathrm{C}_{10} \mathrm{H}_{20} \mathrm{O}\right)$ will be considered to be the same as the response for $n$-nonane $\left(\mathrm{C}_{9} \mathrm{H}_{20}\right)$ because one of the carbon atom linked to the oxygen from the ether group is not detected, whereas other of carbon atoms are.

\section{Nature of the reaction products}

In this section, the nature of the products that were identified during the study of the oxidation of pure $\mathrm{n}$-decane and both surrogate blends is described. 


\subsection{Pure n-decane}

Light products $\left(\mathrm{C}_{0}-\mathrm{C}_{5}\right)$ quantified during the oxidation of $\mathrm{n}$-decane have already been discussed in a previous paper [7]. These products were methane, acetylene, ethylene, ethane, propyne, allene, propene, propane, 1,3-butadiene, 1,2-butadiene, 1-butene, n-butane, 1-pentene, carbon monoxide, carbon dioxide, methanol, ethanol, acetaldehyde, propanal, and acetone.

The formation of large olefins was also observed. These olefins were 1-hexene, 1-heptene, 1-octene, 1-nonene, and five $C_{10}$ isomers: 1-decene, 4-decene (Z), 3-decene (E), 2-decene (E), and 2-decene (Z). Two isomers of conformation were identified for 2-decene but only one isomer was identified for 3and 4-decenes. The formation of 5-decenes was not observed.

Fig. 1 displays part of a chromatogram showing the peaks corresponding to $C_{10}$ oxygenated compounds formed at low temperature (chromatogram obtained for an experiment at $650 \mathrm{~K}$ ). It can be seen that some peaks are not well separated. This is because these species have the same molecular weight (156 $\mathrm{g} \mathrm{mol}^{-1}$ ) and very similar structures. They are cyclic ethers (with 6-, 5- and 4membered rings), decanones, and decanal. Names and structures of these species are given in Table 2. The formation of cyclic ethers during the oxidation of $n$-decane has already been observed by Dagaut et al. [33]. The identification of cyclic ethers has been performed by the deciphering of their mass spectra, which are missing in all available databases. Fig. 2 displays the rules of fragmentation forming the main larger fragments in electronic impact mass spectrometry for 5-membered ring cyclic ethers. These rules have been deduced from the rules proposed for species including oxygen atoms, such as ketones [34, p. 178]. The ionization of the ether molecule leads to an ion with a positive charge and a radical center carried by the oxygen atom. This ion-radical can then react by $\beta$-scission decomposition; two smaller positive ions can be obtained. It is worth noting that the $\beta$-scission does not occur if $R_{1}$ or $R_{2}$ is a methyl group or a hydrogen atom (the corresponding bond energies are too high). To illustrate this, expected fragments for 5 -membered ring cyclic ethers $A, B$, $C$, and $M$ of Table 2 are listed in Table 3. The mass spectra that were obtained for these species are in agreement with the rules presented above, because the peaks corresponding to the expected fragments are present. The mass spectrum of 2,5-dipropyl-tetrahydrofuran was available in the "NBS75 K" database, allowing confirmation for the identification of this species. Fig. 3 displays the mass spectrum obtained for 2-ethyl-5-butyl-tetrahydrofuran. We can observe the peaks corresponding to the two expected larger fragments ( 99 and $127 \mathrm{~g} \mathrm{~mol}^{-1}$ ). We can also observe two large peaks of mass 81 and 109, which could correspond to the loss of a fragment of $18 \mathrm{~g} \mathrm{~mol}^{-1}$. It was not possible to determine the mechanism responsible for this loss. It is worth noting that each cyclic ether appears twice on the chromatogram of the Fig. 1. This is because two isomers (cis and trans) can be obtained. It has not been possible to distinguish between these two isomers. 


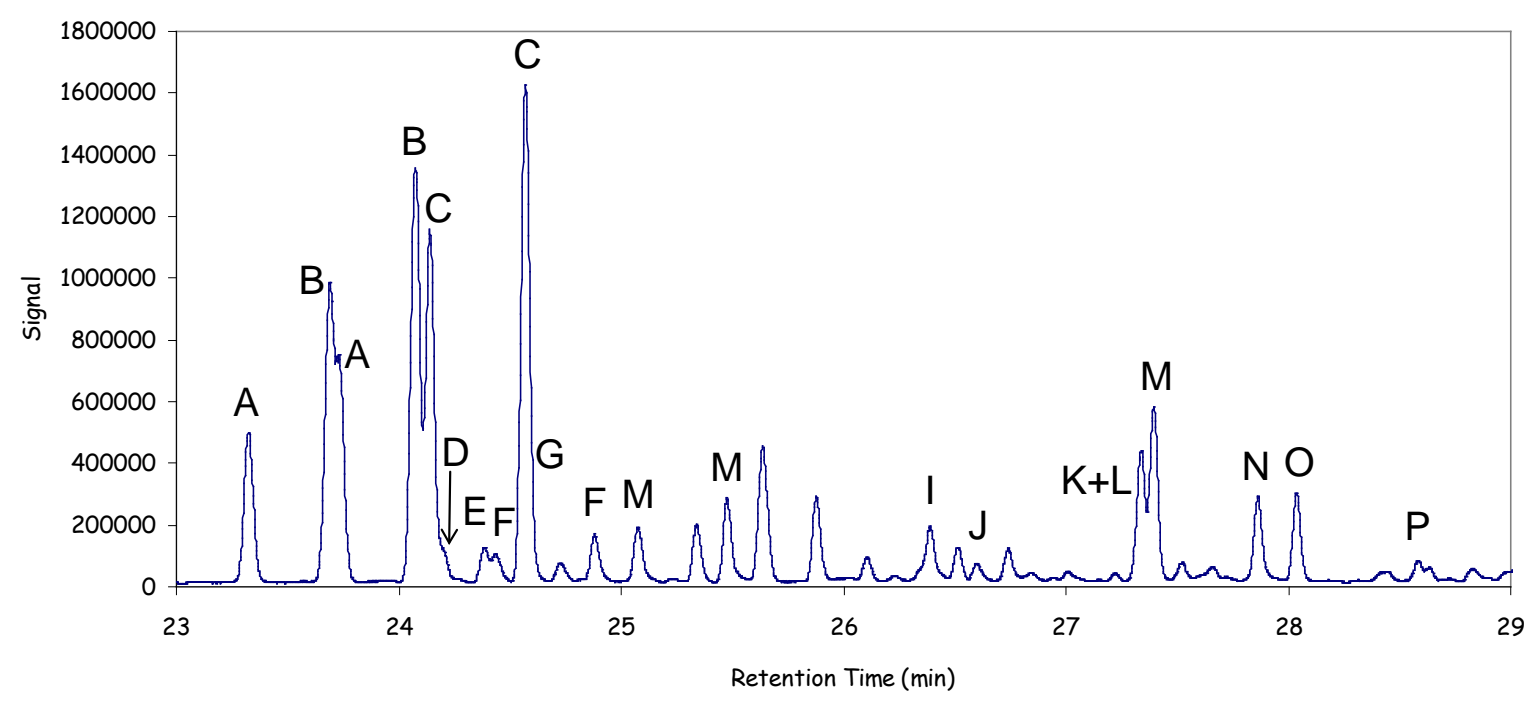

Fig. 1. Part of a chromatogram showing the peaks corresponding to $\mathrm{C} 10$ oxygenated compounds ( $\mathrm{n}$-decane oxidation, experiment at $\mathrm{T}=650 \mathrm{~K}, \tau=1.5 \mathrm{~s}$, and $\mathrm{P}=106 \mathrm{kPa}$ ). The names of the compounds corresponding to the letters in the chromatogram are given in Table 2.
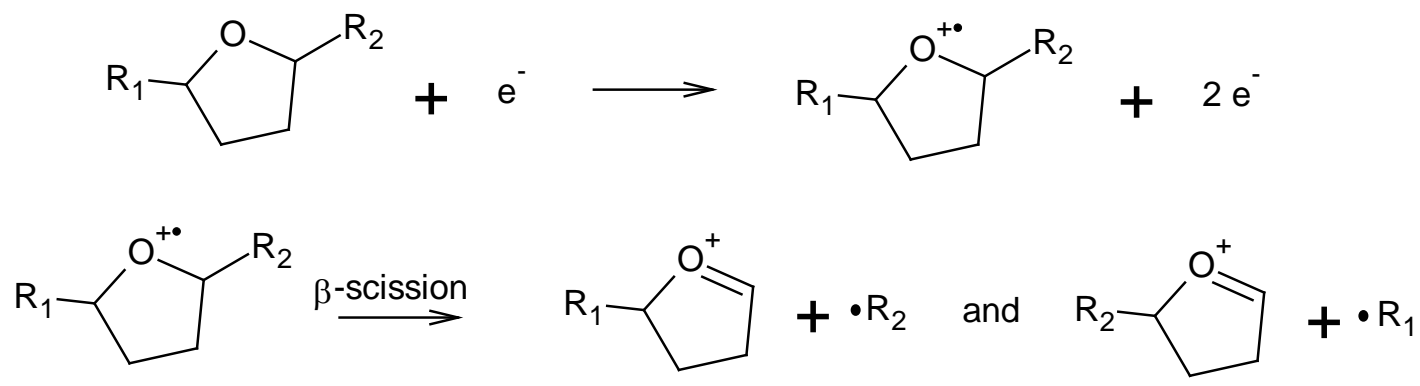

Fig. 2. Rules of fragmentation of five membered ring cyclic ethers in electronic impact mass spectrometry. 
Table 2. Oxygenated compounds identified in the chromatogram of Fig. 1.

\begin{tabular}{|c|c|c|c|}
\hline $\begin{array}{c}\text { Letter on the chromatogram of } \\
\text { Figure } 1\end{array}$ & Species name & Species structure & \\
\hline A & 2,5-dipropyl-tetrahydrofuran & & \\
\hline B & $\begin{array}{l}\text { 2-ethyl,5-butyl- } \\
\text { tetrahydrofuran }\end{array}$ & & \\
\hline C & $\begin{array}{l}\text { 2-methyl,5-pentyl- } \\
\text { tetrahydrofuran }\end{array}$ & & \\
\hline D & $\begin{array}{l}\text { 2-ethyl,6-propyl- } \\
\text { tetrahydropyran }\end{array}$ & & \\
\hline E & 2-methyl,5-hexyl-oxetan & & \\
\hline $\mathrm{F}$ & 2-ethyl,5-pentyl-oxetan & & \\
\hline G & $\begin{array}{l}\text { 2-methyl,6-butyl- } \\
\text { tetrahydropyran }\end{array}$ & & $l_{3}$ \\
\hline $\mathrm{H}$ & 2-propyl,5-butyl-oxetan & & \\
\hline 1 & 2-heptyl-oxetan & & $H_{3}$ \\
\hline $\mathrm{J}$ & 2-pentyl-tetrahydropyran & & \\
\hline K & 4-decanone & & \\
\hline $\mathrm{L}$ & 5-decanone & & \\
\hline M & 2-hexyl-tetrahydrofuran & & \\
\hline $\mathrm{N}$ & 3-decanone & & \\
\hline 0 & 2-decanone & & \\
\hline $\mathrm{P}$ & decanal & & $\mathrm{CH}_{3}$ \\
\hline
\end{tabular}


Table 3. Expected fragments for $C_{10}$ tetrahydrofurans.

\begin{tabular}{|c|c|c|}
\hline Cyclic ether & $\begin{array}{c}\text { Obtained fragments according to rules presented in } \\
\text { Figure } 2\end{array}$ & Comments \\
\hline $\begin{array}{l}\text { 2,5-dipropyl- } \\
\text { tetrahydrofuran }\end{array}$ & & $\begin{array}{l}\text { The molecule is symmetric. } \\
\text { Only one main fragment is } \\
\text { expected }\left(113 \mathrm{~g} \cdot \mathrm{mol}^{-1}\right)\end{array}$ \\
\hline $\begin{array}{l}\text { 2-ethyl,5-butyl- } \\
\text { tetrahydrofuran }\end{array}$ & & $\begin{array}{l}\text { Two fragments are expected } \\
\left(99 \text { and } 127 \mathrm{~g} \cdot \mathrm{mol}^{-1} \text { ) }\right.\end{array}$ \\
\hline $\begin{array}{l}\text { 2-methyl,5- } \\
\text { pentyl- } \\
\text { tetrahydrofuran }\end{array}$ & & $\begin{array}{l}\text { Only one main fragment is } \\
\text { expected }\left(85 \mathrm{~g} \cdot \mathrm{mol}^{-1}\right)\end{array}$ \\
\hline $\begin{array}{l}\text { 2-hexyl- } \\
\text { tetrahydrofuran }\end{array}$ & & $\begin{array}{l}\text { Only one main fragment is } \\
\text { expected }\left(71{\mathrm{~g} \cdot \mathrm{mol}^{-1}}^{-1}\right)\end{array}$ \\
\hline
\end{tabular}

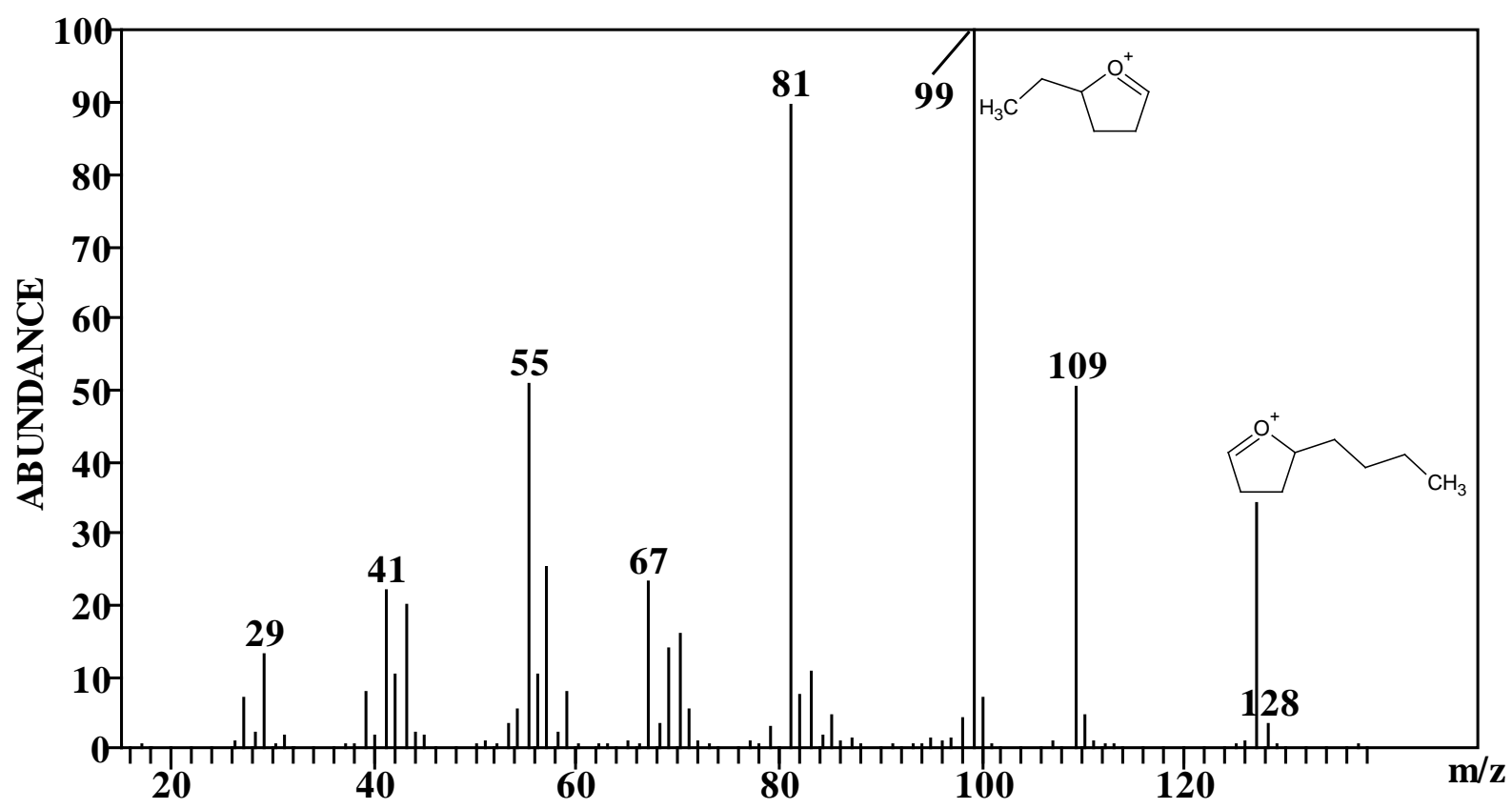

Fig. 3. Mass spectrum of 2-ethyl,5-butyl-tetrahydrofuran. 


\section{2. $\mathrm{n}$-Decane/n-hexadecane blend}

Light products $\left(\mathrm{C}_{0}-\mathrm{C}_{5}\right)$ formed during the oxidation of the $\mathrm{n}$-decane/n-hexadecane blend are the same as the products which have been listed in the section about n-decane. As far as heavier products are concerned, species formed by the oxidation of $n$-decane have also been observed with the $n$-decane/n-hexadecane blend. Because of the presence of $n$-hexadecane, olefins larger than decenes have been identified. These new olefins are 1-alkenes from 1-undecene to 1-pentadecene. Because of the low initial mole fraction of $n$-hexadecane and the large number of isomers, we could not detect the formation of isomers of the 1-hexadecene, although their formation was expected (FID detection limit: 0.1 ppm).

The formation of oxygenated species has also been observed at low temperature. Only $\mathrm{C}_{16}$ 5-membered ring cyclic ethers and $C_{16}$ ketones have been detected (molecular weight of $240 \mathrm{~g}$ $\mathrm{mol}^{-1}$ ). As expected, we identified seven different $\mathrm{C}_{16} 5$-membered ring cyclic ethers, with six of them being present twice on the chromatogram (cis and trans isomers). These species are: 2-dodecyl-tetrahydrofuran, 2-methyl-5-undecyl-tetrahydrofuran, 2-ethyl-5-decyl-tetrahydrofuran, 2-propyl-5-nonyl-tetrahydrofuran, 2-butyl-5-octyl-tetrahydrofuran, 2-pentyl-5-heptyltetrahydrofuran, and 2,5-dihexyl-tetrahydrofuran. We expected the formation of seven $\mathrm{C}_{16}$ ketones and hexadecanal but we detected only four ketones: 2-hexadecanone, 4-hexadecanone, 8-hexadecanone, and 6-hexadecanone or 5-hexadecanone.

\section{3. n-Decane/methyl palmitate blend}

Light species observed during the studies of the oxidation of $n$-decane and of the $\mathrm{n}$-decane/n-hexadecane blend were also detected during the study of the oxidation of the n-decane/methyl palmitate blend.

The formation of large olefins and unsaturated esters was also observed. These large olefins are 1-alkenes from 1-hexene to 1-pentadecene $\left(\mathrm{C}_{15} \mathrm{H}_{30}\right)$ and decene isomers. The formation of these species was expected because the alkyl chain of methyl palmitate has 15 atoms of carbon. It is worth noting that 1-alkenes from 1-hexene to 1-decene can be formed from both $\mathrm{n}$-decane and methyl palmitate, that other decene isomers should come from $n$-decane only, and that larger olefins from 1-undecene to 1-pentadecene come from methyl palmitate only. Unsaturated esters are esters with one double bond at the extremity of the alkyl chain. The smallest one is methyl acrylate $\left(\mathrm{C}_{4} \mathrm{H}_{6} \mathrm{O}_{2}\right)$ and the largest one is methyl 14-pentadecenoate $\left(\mathrm{C}_{16} \mathrm{H}_{30} \mathrm{O}_{2}\right)$. The formation of isomers of methyl 5 -hexadecenoate has not been observed. This is likely due to the fact that the initial mole fraction of methyl palmitate is lower than the initial mole fraction of $n$-decane and that the number of possible isomers is larger. The structures of these unsaturated esters are shown in Table 4. Mass spectra of 
1-alkenes were included in the "NBS75 K" database, whereas the mass spectrum of methyl 10-undecenoate $\left(\mathrm{C}_{12} \mathrm{H}_{22} \mathrm{O}_{2}\right)$ was the only one available for unsaturated ester. This mass spectrum was of great help for the identification of the peak corresponding to the methyl 10-undecenoate and for deciphering the mass spectra of the other unsaturated esters. It is worth noting that these spectra have a large peak at $74 \mathrm{~g}$ moll and another characteristic peak corresponding to a loss of $74 \mathrm{~g}$ $\mathrm{mol}^{-1}$. The formation of these fragments can be explained by a rearrangement of McLafferty (well known for ketones and aldehydes) adapted to esters from [34, p. 182], as shown in Fig. 4. This rearrangement consists in the transfer of an $\mathrm{H}$-atom on the cation-radical center through a 6-membered ring transition state. Fig. 5 displays the mass spectrum we obtained for methyl 11-dodecenoate (212 $\mathrm{g} \mathrm{mol}-1)$. The peak at $74 \mathrm{~g} \mathrm{~mol}^{-1}$ and the peak at $138 \mathrm{~g} \mathrm{~mol}^{-1}(=212-74)$ are present.

Table 4. List of the unsaturated esters detected during the study of the oxidation of the ndecane/methyl palmitate blend.

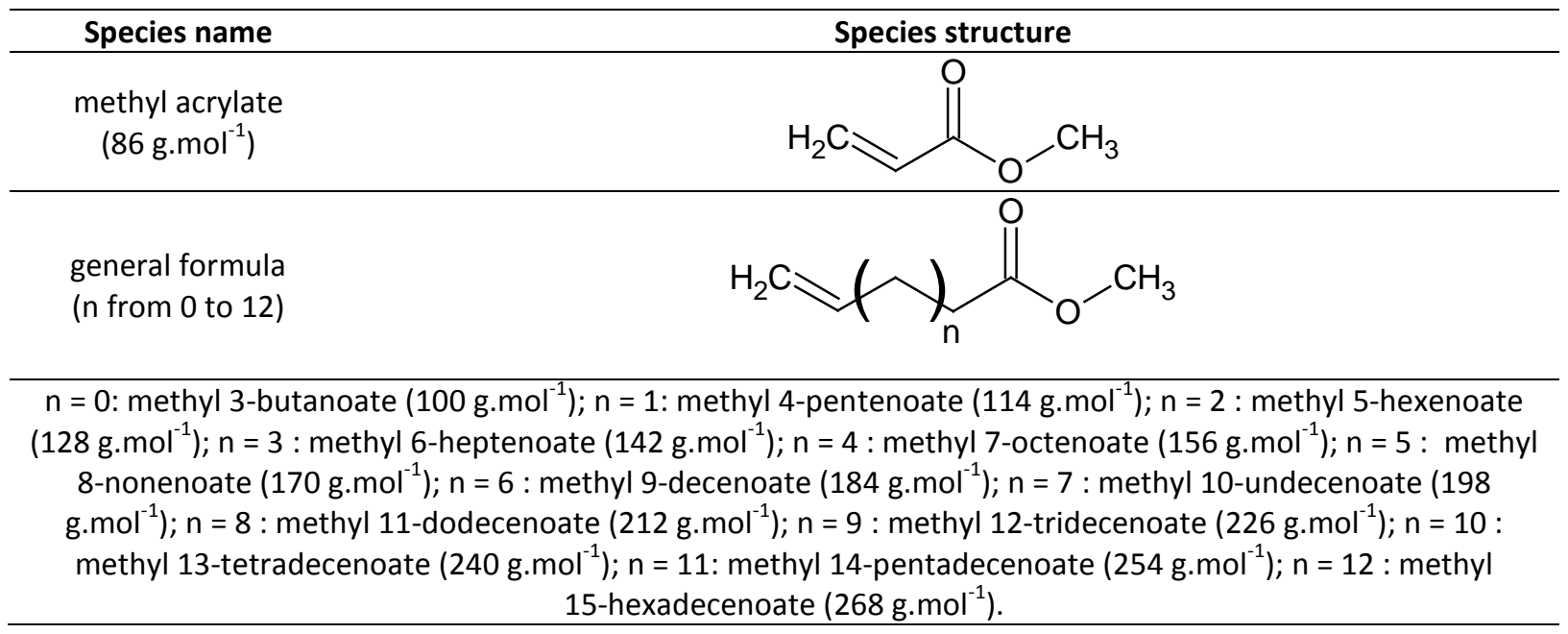

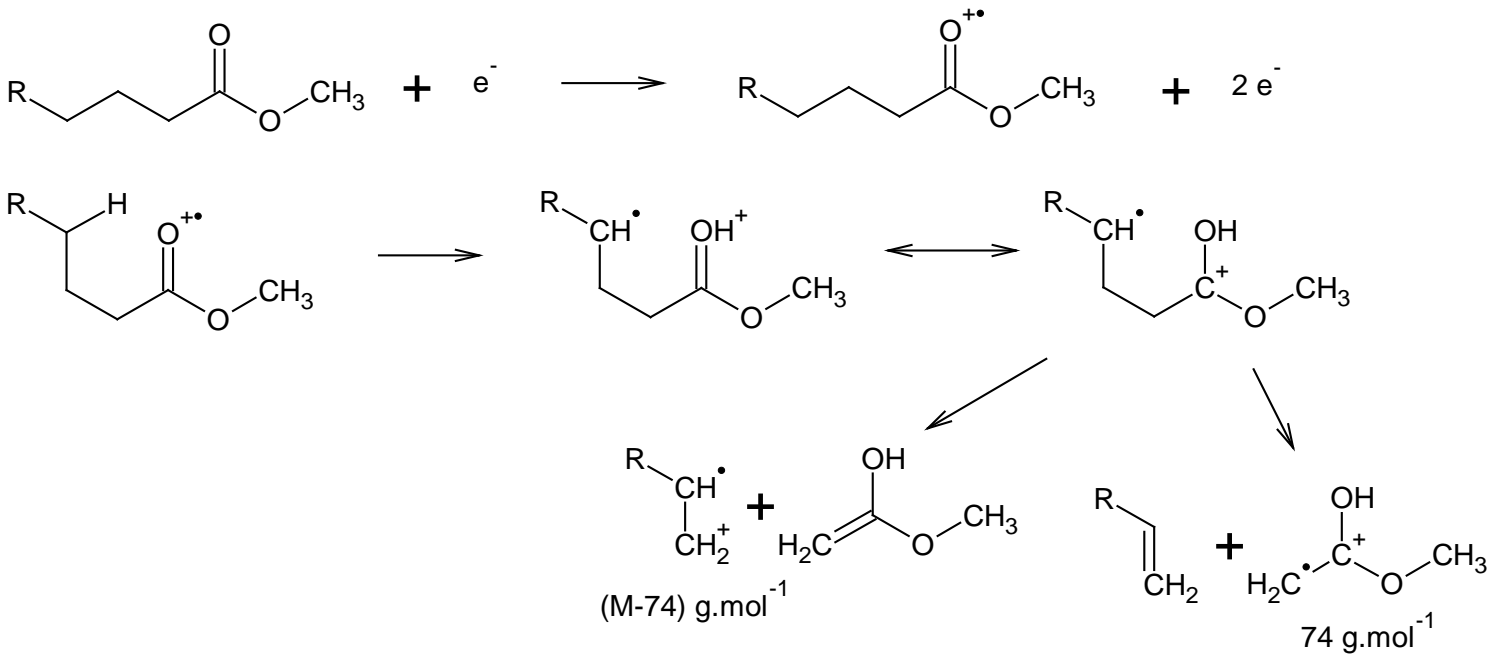

Fig. 4. Rearrangement of McLafferty adapted to esters from [34]. 


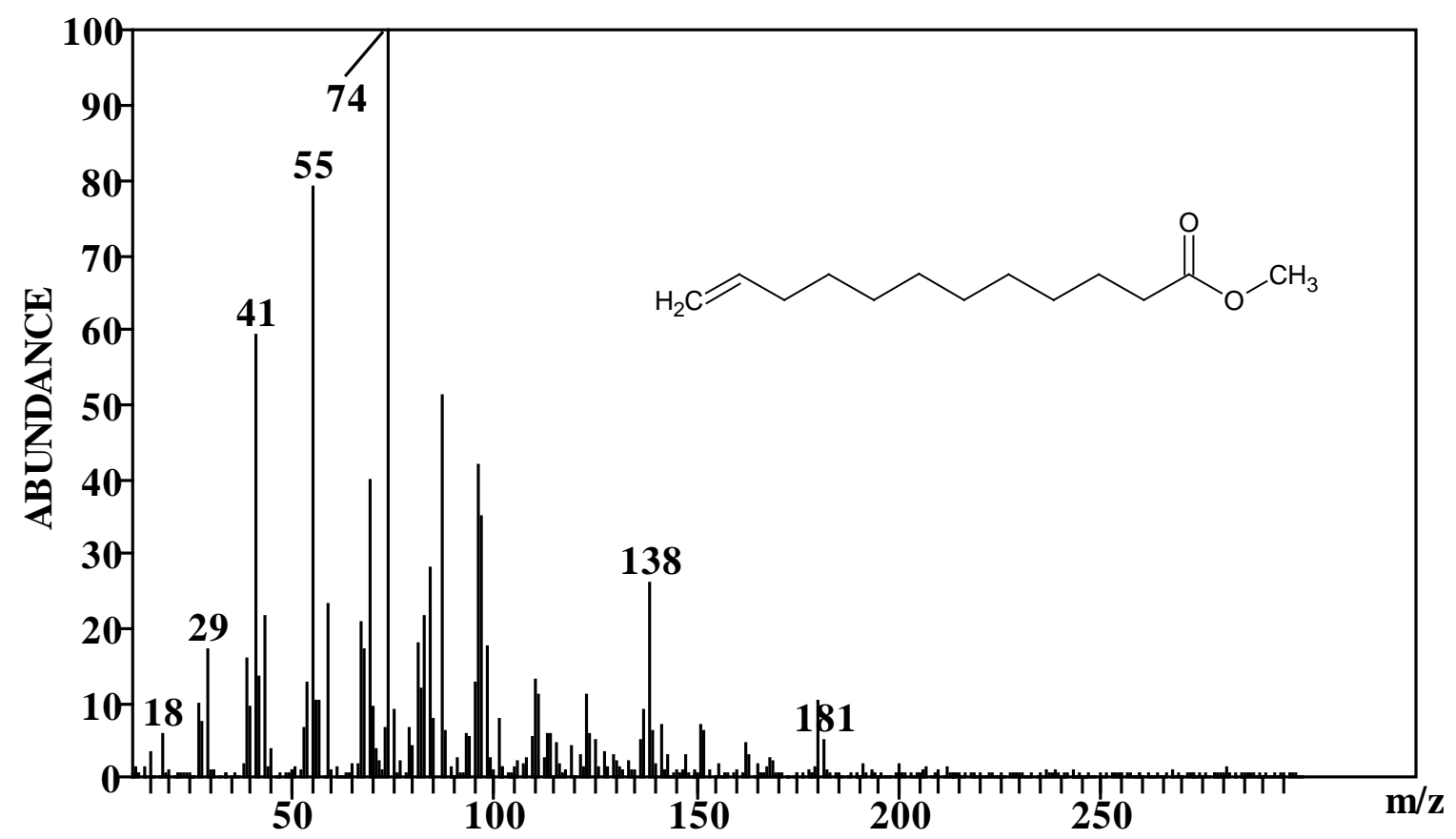

Fig. 5. Experimental mass spectrum of methyl 11-dodecenoate $\left(212 \mathrm{~g} \mathrm{~mol}^{-1}\right)$.

The formation of oxygenated compounds has also been observed at low temperature. As in the case of the study of $\mathrm{n}$-decane and of the $\mathrm{n}$-decane/ $\mathrm{n}$-hexadecane blend, we observed the formation of the same $C_{10}$ oxygenated species. We also observed the formation of $C_{17} 5$-membered ring cyclic ethers $\left(284 \mathrm{~g} \mathrm{~mol}^{-1}\right)$ coming from methyl palmitate. Other cyclic ethers, ketones, and aldehydes have not been observed. This is likely due to the low initial mole fraction of methyl palmitate in the blend. As expected, we identified 13 different $\mathrm{C}_{17}$ 5-membered ring cyclic ethers. Among them 11 appears twice during the analysis (isomers cis and trans). This large number of species is due to the loss of symmetry in esters compared to n-alkanes. Peaks corresponding to these species are shown on the chromatogram in Fig. 6 . It can be noted that the peaks are not well separated due to the similarities of the structures (the structures of these cyclic ethers are shown in Table 5). It is worth noting that even the formation of the cyclic ether with the ester group included in the ring has been observed (species $L$ in Table 5). For the identification of these species we used the same rules of fragmentation as in the rules presented above in the case of cyclic ethers deriving from $\mathrm{n}$-decane. 


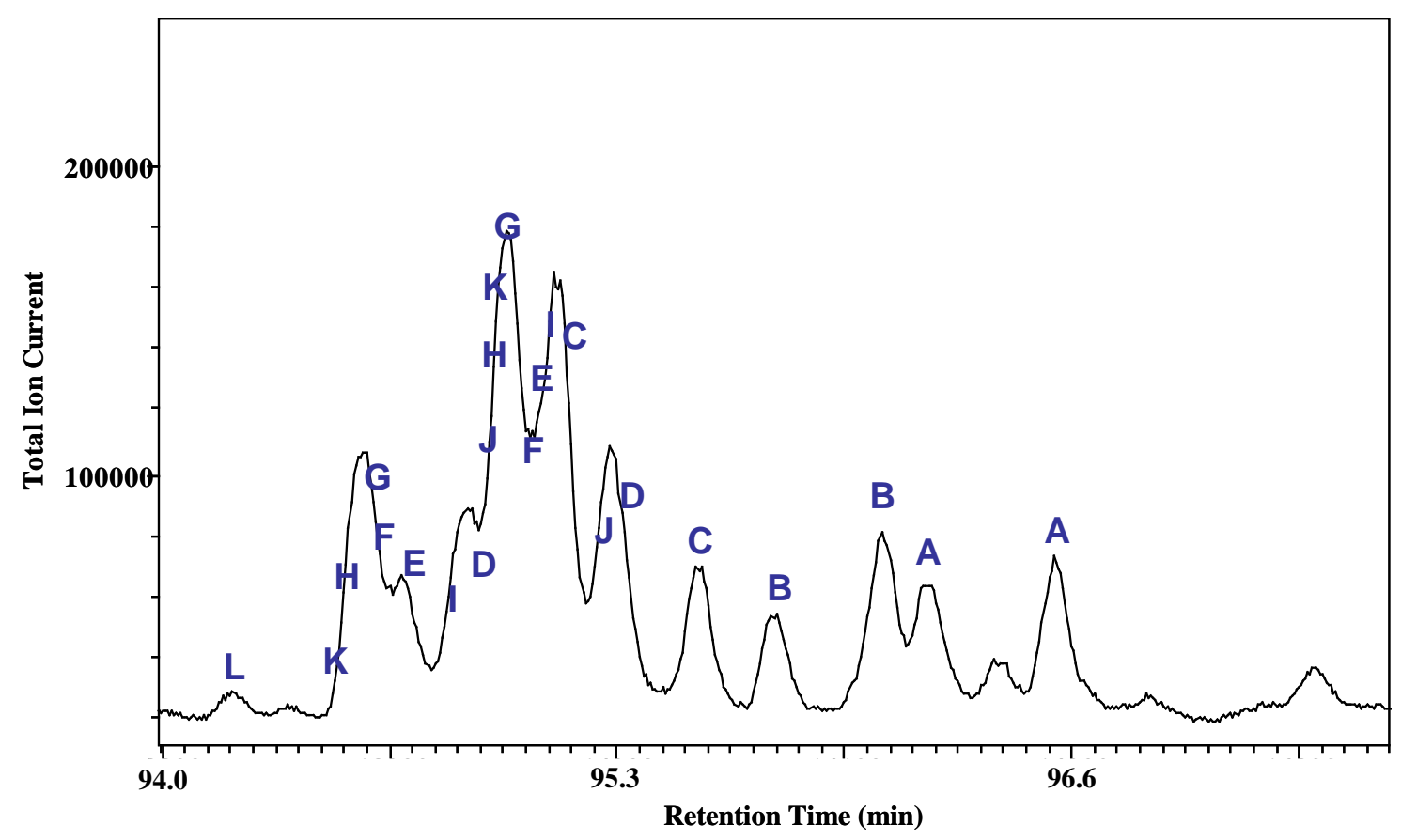

Fig. 6. Extract of a chromatogram showing the peaks corresponding to the $\mathrm{C}_{17}$ cyclic ethers ( $\mathrm{n}$-decane/methyl palmitate blend, $\mathrm{T}=650 \mathrm{~K}, \tau=1.5 \mathrm{~s}, \mathrm{P}=106 \mathrm{kPa}$ ). The names of the compounds corresponding to the letters in the chromatogram are given in Table 5. 
Table 5. List of the $\mathrm{C}_{17}$ cyclic ethers detected during the study of the oxidation of the n-decane/methyl palmitate blend.

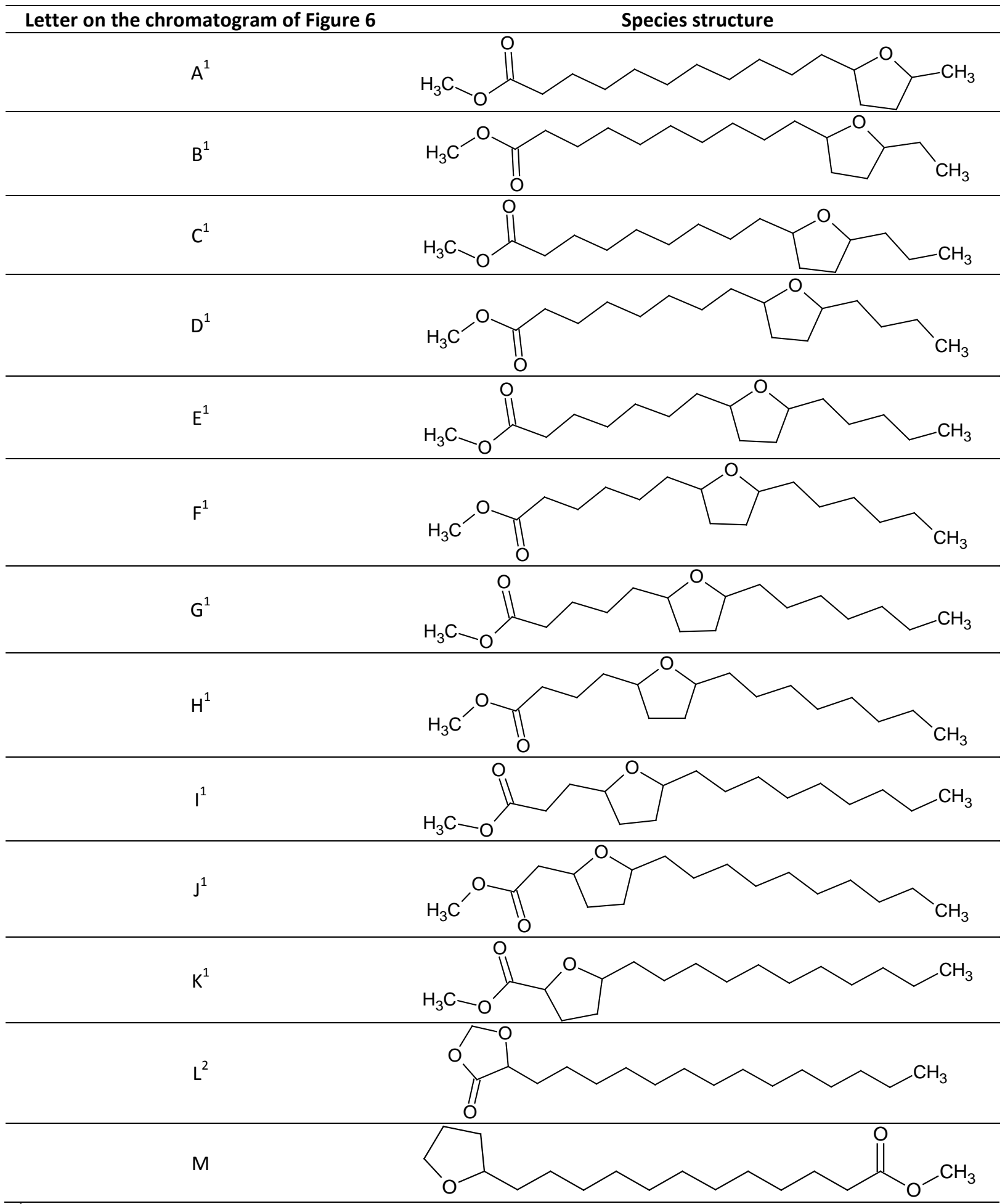

\footnotetext{
${ }^{1}$ Two isomers (cis and trans) have been detected (see chromatogram in Figure 6).

${ }^{2}$ Cyclic ether with the ester group included in the ring.
} 


\section{Results and discussion}

The conversion and the mole fraction profiles of light species formed by the oxidation of $n$-alkanes have already been presented in a former paper for $n$-decane and the $n$-decane/n-hexadecane blend [6]. Experimental results concerning heavy species formed during the oxidation of $n$-decane and $\mathrm{n}$-decane/n-hexadecane are new as well as all experimental results obtained during the study of the n-decane/methyl palmitate blend.

Most experiments were performed at least twice in order to verify the repeatability of the experimental results. Repeatability was satisfactory over the whole range of studied temperatures, as the difference in the measured mole fractions was always less than $20 \%$.

Carbon atom balances were calculated in order to verify that the mass of carbon in the species at the outlet of the reactor matched the mass of carbon in the reactants at the inlet of the reactor. Comparison of the total mass (carbon, hydrogen, and oxygen) of the reactant and of the total mass of the species at the outlet of the reactor could not be performed, because some important species containing hydrogen and oxygen atoms, such as water, were not quantified. For experiments performed at temperatures below $550 \mathrm{~K}$ and above $700 \mathrm{~K}$ the agreement between the mass of carbon in the reactants at the inlet of the reactor and the mass of carbon in the species at the outlet was satisfactorily for both surrogate fuels (ratios of carbon masses were in the range 95-105\%). In the low temperature region between 550 and $700 \mathrm{~K}$, the mass of carbon in the species at the outlet of the reactor was less than expected (mass ratios around $70 \%$ ). The reason for this variation is that the conversion is important and the reaction leads to the formation of numerous oxygenated products, among which some species were not quantified because of too low mole fractions (e.g., formaldehyde, cyclic ethers, ketones, aldehydes, species with two oxygen atoms). Another reason for the variation is the loss of heavy species, which may condense on the wall of the outlet of the reactor.

\subsection{Reactivity of large $n$-alkanes and methyl esters}

The comparison of the experimental results obtained during the studies of the oxidation of pure ndecane and the oxidation of the blend of $\mathrm{n}$-decane and $\mathrm{n}$-hexadecane showed that the conversion of $\mathrm{n}$-decane was very close in both studies [7]. Once again, this statement is valid for the conversion of $\mathrm{n}$-decane in the blend of $\mathrm{n}$-decane and methyl palmitate (Fig. 7). 


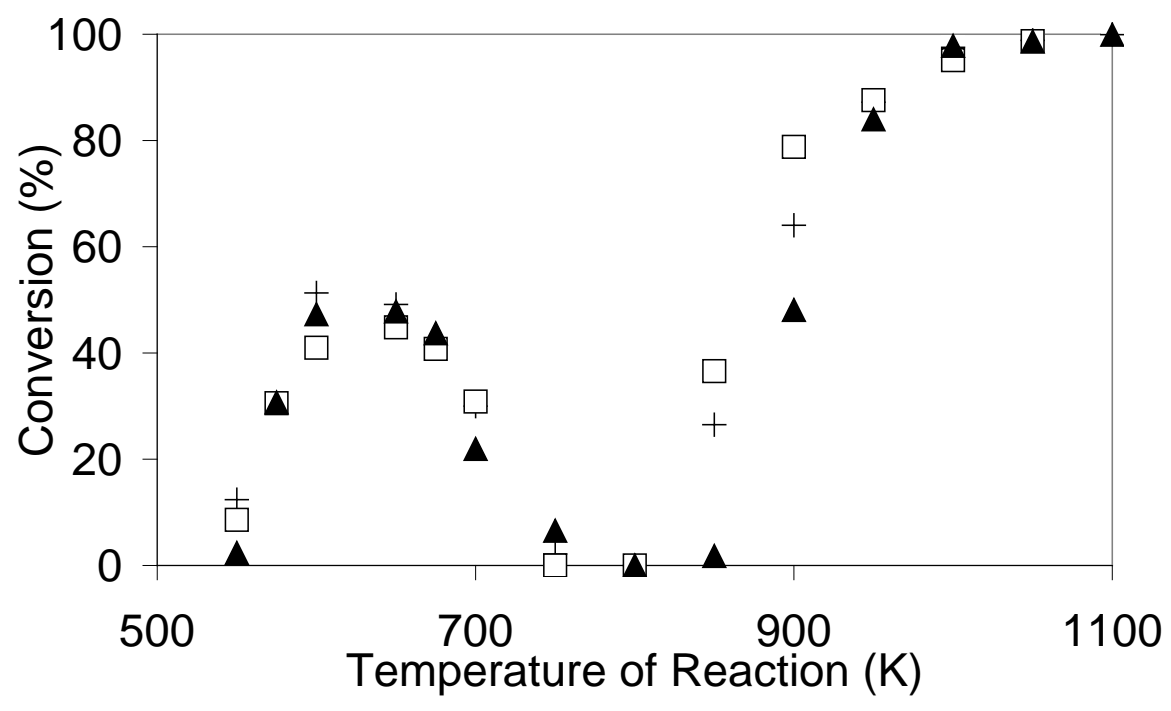

Fig. 7. Comparison of experimental conversions of $n$-decane for the three reacting fuels. + neat $\mathrm{n}$-decane; $\square \mathrm{n}$-decane/n-hexadecane; $\boldsymbol{\Delta}$ n-decane/methyl palmitate.

Conversions of $n$-hexadecane and methyl palmitate are displayed in Fig. 8. It can be seen that these two species have very close reactivities over the whole range of temperatures and that they exhibit the same NTC behavior than n-decane. NTC means negative temperature coefficient and corresponds to the temperature region where the reactivity of a species decreases and then increases again when the temperature goes up. Before the NTC region (less than $750 \mathrm{~K}$ ) their conversions are slightly larger than the conversions measured for $\mathrm{n}$-decane: maximum conversion is around $50 \%$ for $\mathrm{n}$-decane and $65 \%$ for $\mathrm{n}$-hexadecane and methyl palmitate at $650 \mathrm{~K}$. At higher temperatures all species exhibit similar reactivities.

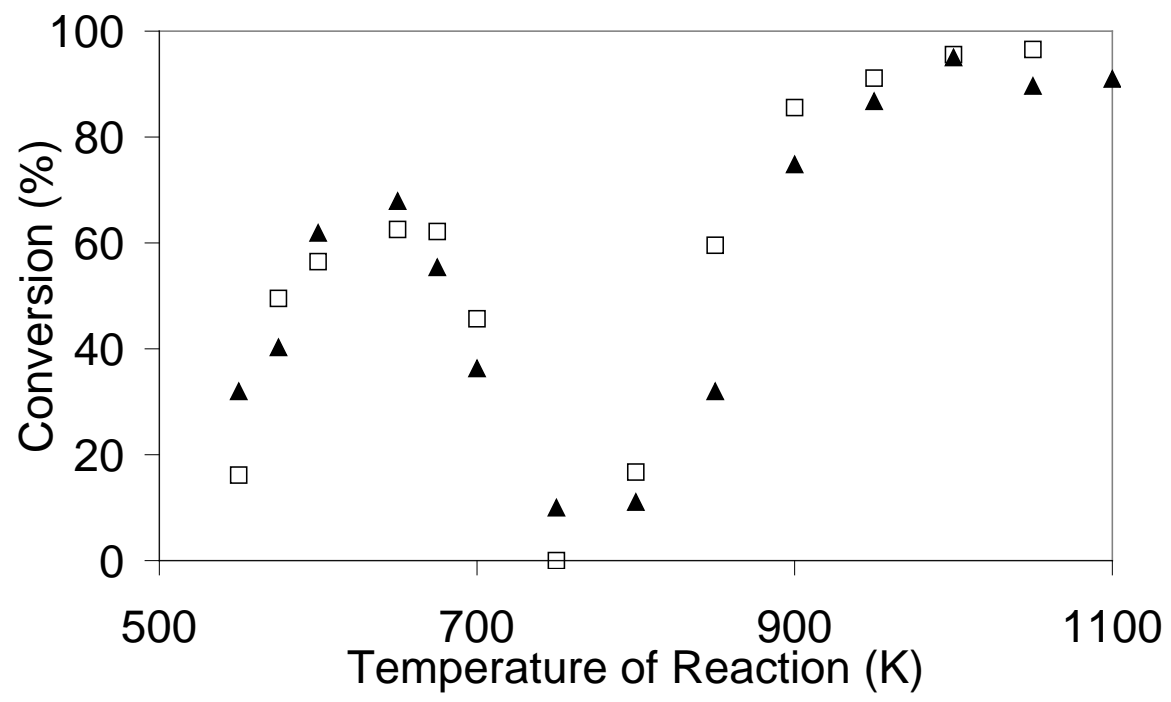

Fig. 8. Comparison of experimental conversions of $\square \mathrm{n}$-hexadecane (in the $n$-decane/n-hexadecane blend) and up triangle, filled methyl palmitate (in the $n$-decane/methyl palmitate blend). 


\subsection{Evolution of the mole fractions of the reaction products obtained with neat $n$-decane}

The evolution of the mole fractions of light reaction products from the oxidation of neat $\mathrm{n}$-decane has already been described in a previous paper [7]. Fig. 9 displays the evolution of alkenes: 1-octene, 1-nonene, and isomers of decene (1-decene, 2-decene (E), 2-decene (Z), 3-decene, and 4-decene). All these species exhibit a NTC behavior. Mole fractions of isomers of decene are more important below the NTC than above. These relatively high mole fractions at low temperature can be explained by the oxidation reactions of $n$-decyl radicals deriving from the parent molecule $\left(\mathrm{C}_{10} \mathrm{H}_{21}+\mathrm{O}_{2}=\mathrm{C}_{10} \mathrm{H}_{20}+\mathrm{HO}_{2}\right)$. Fig. 10 displays the evolution of the mole fractions of large oxygenated compounds (cyclic ethers, ketones, and aldehydes). These species are formed at low temperature, as is visible for the $\mathrm{C}_{10} \mathrm{cyclic}$ ether $A$ in Table 2. All $C_{10}$ cyclic ethers are formed in very close quantity except the cyclic ether $M$ in Table 2, which is present in a smaller amount. The evolution of the mole fractions of 2-decanone is also displayed in Fig. 10. 3-Decanone and 4-decanone are formed in very similar quantities. The formation of 5-decanone has not been observed. Decanal was quantified, but the mole fractions are much smaller than the mole fractions of decanone isomers. Large amounts of octanal were observed during the experiments. 

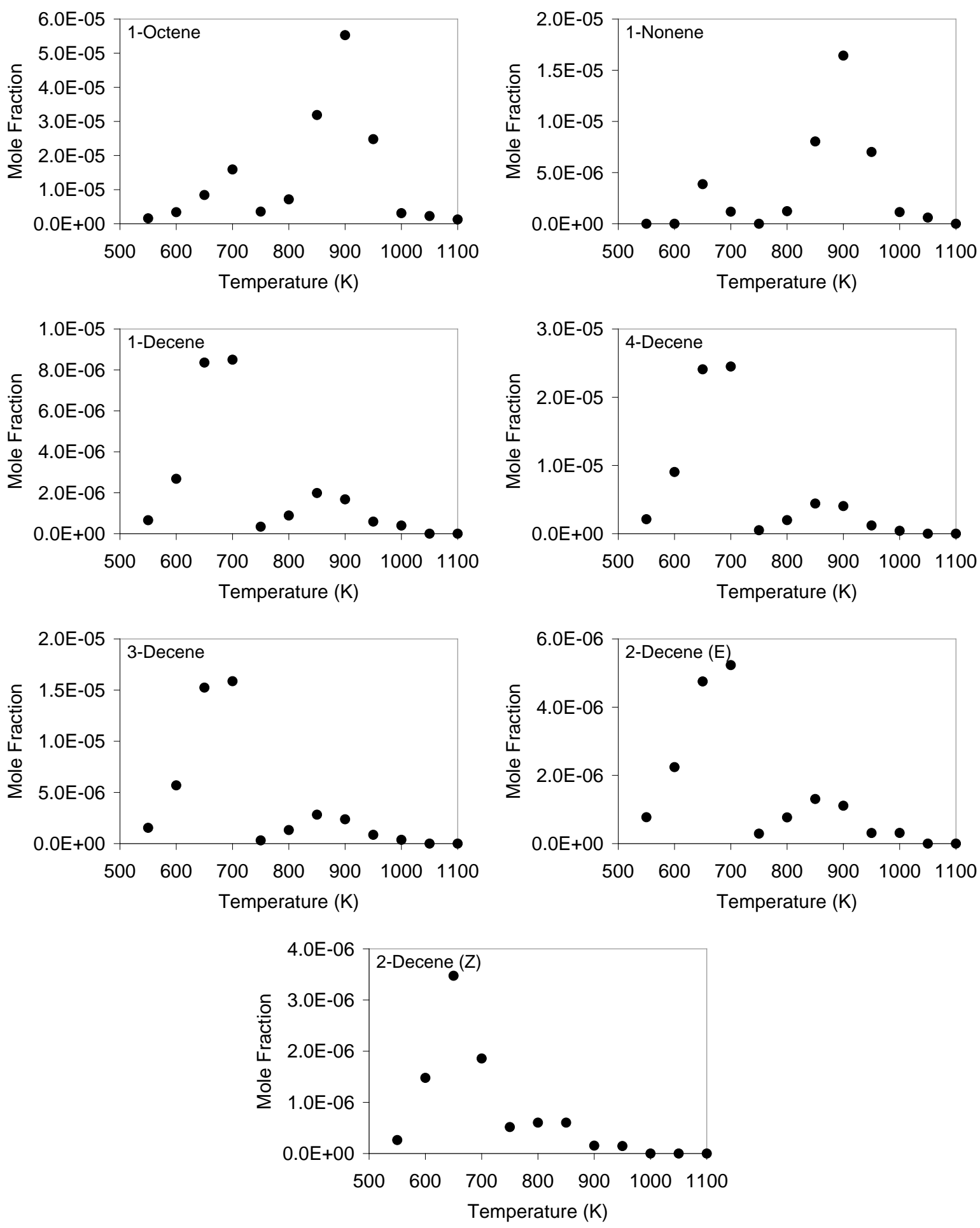

Fig. 9. Evolution of the mole fractions of alkenes formed by the oxidation of neat $\mathrm{n}$-decane. 

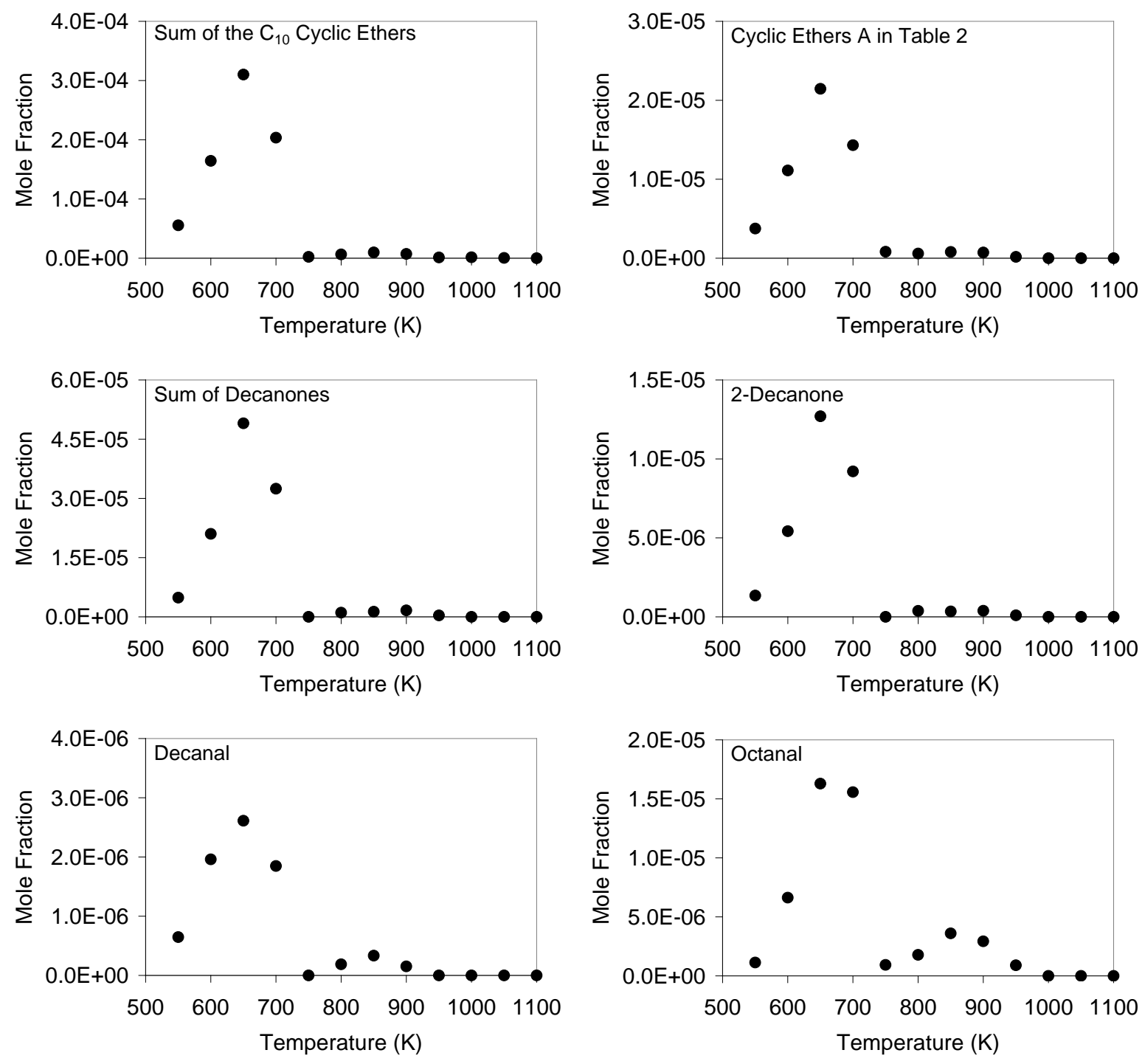

Fig. 10. Evolution of the mole fractions of oxygenated compounds formed by the oxidation of neat n-decane.

\subsection{Comparison of the mole fractions of the reaction products obtained with both blends}

Fig. 11 and Fig. 12 display the mole fractions of the light reaction products. As for the conversion of the reactants (Fig. 7 and Fig. 8), the mole fractions of most species exhibit NTC behaviors. This NTC region is more or less visible according to the species. It is almost invisible for species such as carbon dioxide (Fig. 12) and hydrocarbons (Fig. 11 and Fig. 12) due to the fact that these species are mostly formed at high temperature. Among hydrocarbons it can be seen in Fig. 12 that slight NTC behavior appears from $C_{3}$ and $C_{4}$ species such as propene, 1-butene and 1,3-butadiene. In contrast, the NTC region is very visible for oxygenated species such as carbon monoxide, methanol, acetaldehyde, and propanal (Fig. 11), because these species are formed at both low and high temperatures. 

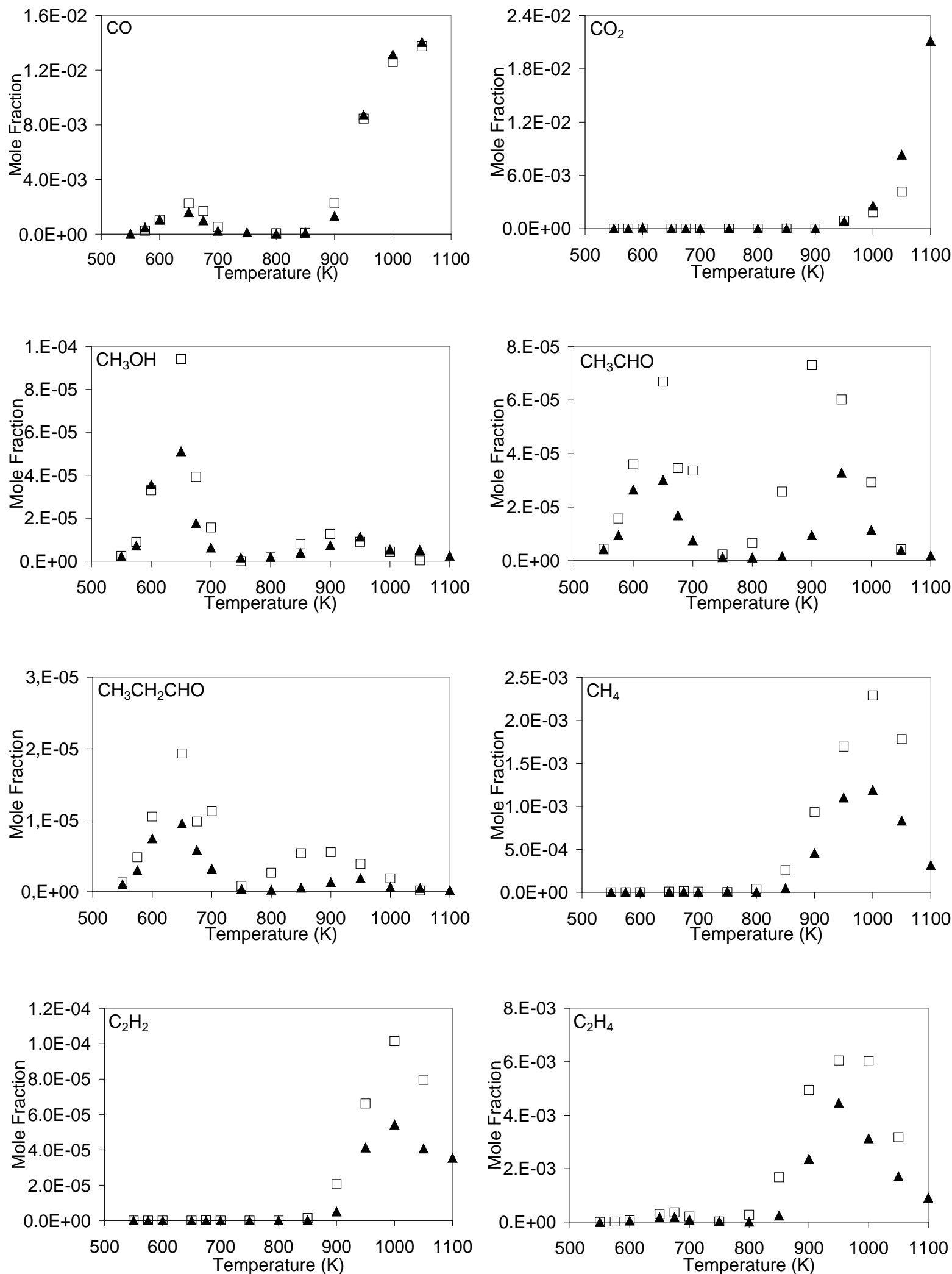

Fig. 11. Evolution and comparison of the mole fractions of carbon oxides, small oxygenated compounds, and small hydrocarbons. $\square \mathrm{n}$-decane/n-hexadecane; $\boldsymbol{\Delta}$-decane/methyl palmitate. 

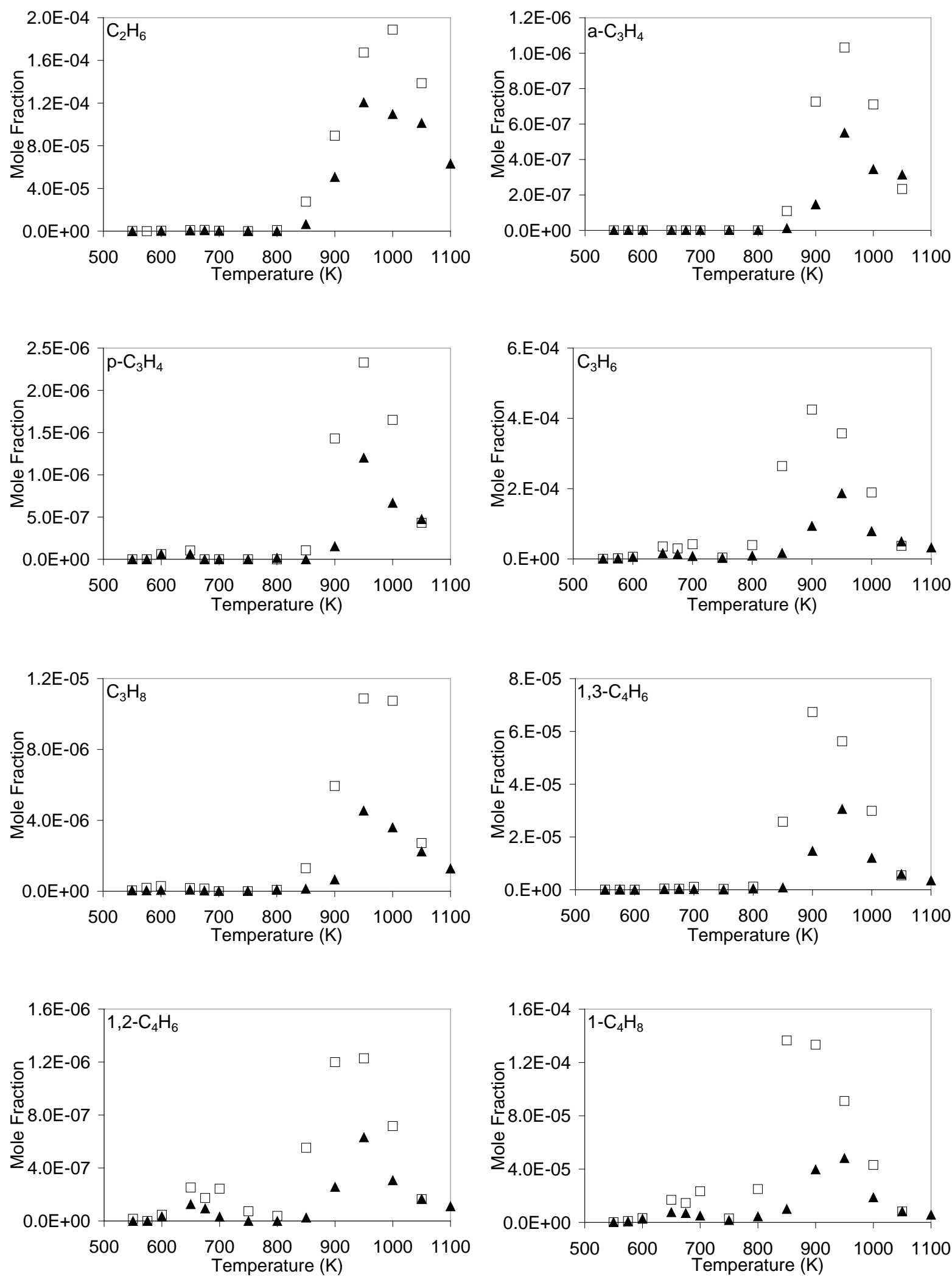

Fig. 12. Evolution and comparison of the mole fractions of hydrocarbons up to $\mathrm{C}_{4}$. n-decane/n-hexadecane; $\Delta$ n-decane/methyl palmitate. 
Light species profiles obtained with both blends (n-decane/n-hexadecane and $\mathrm{n}$-decane/methyl palmitate) have been compared. It can be seen in Fig. 11 that carbon monoxide is the only species for which there is no difference between the two profiles. For carbon dioxide (Fig. 11) profiles are very similar at low and middle temperatures. At higher temperatures (above $950 \mathrm{~K}$ ), the amount of carbon dioxide formed by the reaction seems to be higher for the $\mathrm{n}$-decane/methyl palmitate blend. For other light species, mole fractions are always larger for the $n$-decane/n-hexadecane blend than for the $\mathrm{n}$-decane/methyl palmitate blend.

For heavier 1-alkenes from 1-pentene to 1-pentadecene (Fig. 13), profiles obtained for both blends exhibit a NTC behavior, the only exception being 1-undecene. The NTC behavior of this species could not be observed because 1-undecene could not be quantified with enough accuracy at low temperature (below $800 \mathrm{~K}$ ). Among these species, decene isomers exhibit a particular mole fraction profile: the maximum mole fraction at low temperature is relatively high because of the oxidation reactions of $n$-decyl radicals deriving from the parent molecule. 

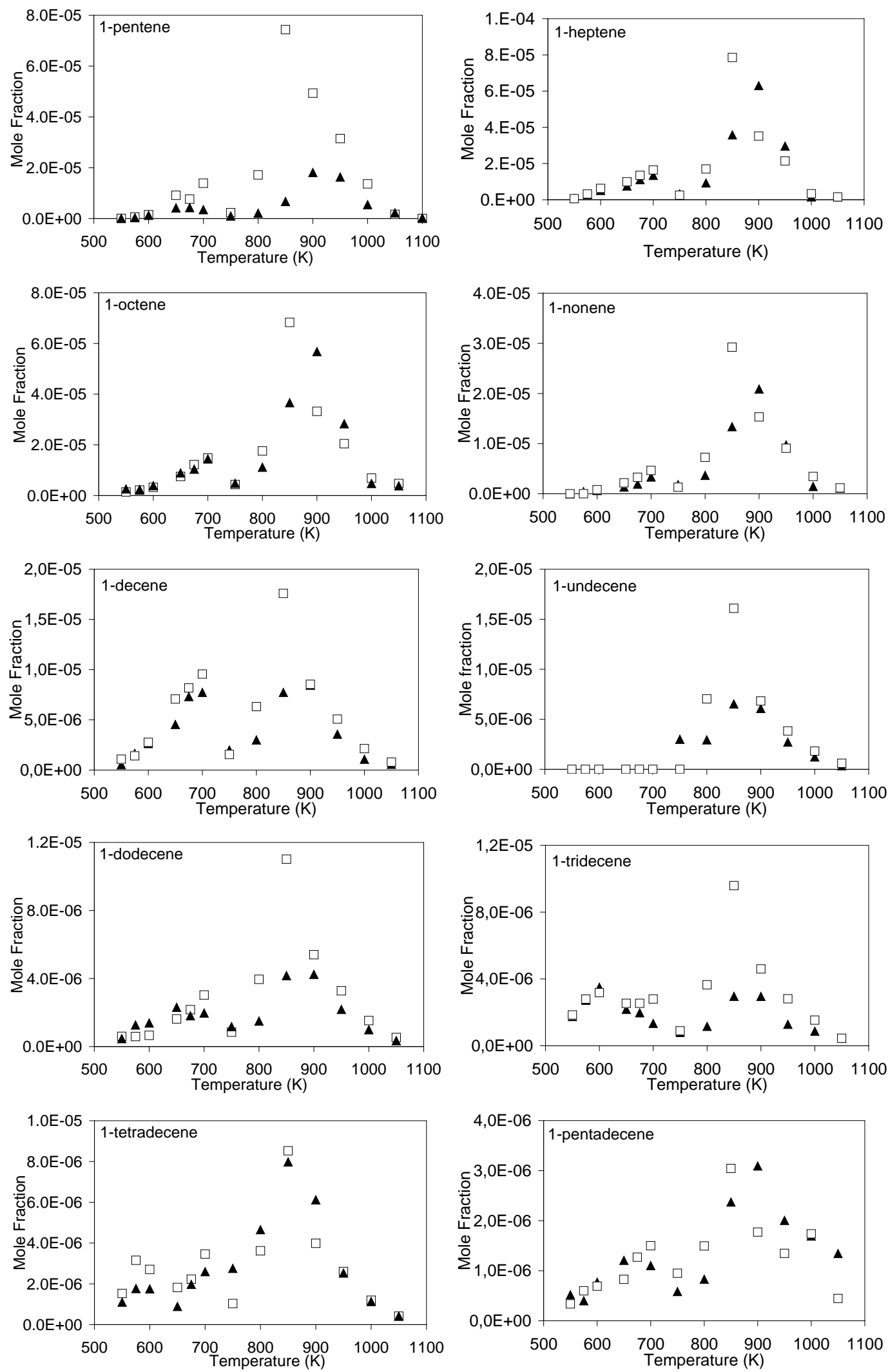

Fig. 13. Evolution and comparison of the mole fractions of heavy 1-alkenes formed by the reaction. $\square$ $\mathrm{n}$-decane/n-hexadecane; up triangle, filled $\mathrm{n}$-decane/methyl palmitate. 
Fig. 12 and Fig. 13 show that mole fractions of 1-alkenes smaller than 1-decene are much larger than mole fractions of 1-decene and larger 1-alkenes, due to the fact that they can be formed from both $\mathrm{n}$-decane and $\mathrm{n}$-hexadecane or methyl palmitate, whereas larger 1-alkenes can only be formed from $\mathrm{n}$-hexadecane or methyl palmitate.

It is worth noting that species mole fractions obtained for both blends are very similar for 1-alkenes larger than 1-heptene. For 1-alkenes lower than 1-heptene (Fig. 13), mole fractions obtained for the $\mathrm{n}$-decane/n-hexadecane blend are higher than mole fractions obtained for the $\mathrm{n}$-decane/methyl palmitate blend. Mole fraction profiles obtained for isomers of decene are also very close (Fig. 14) and very similar to those obtained with neat $\mathrm{n}$-decane.
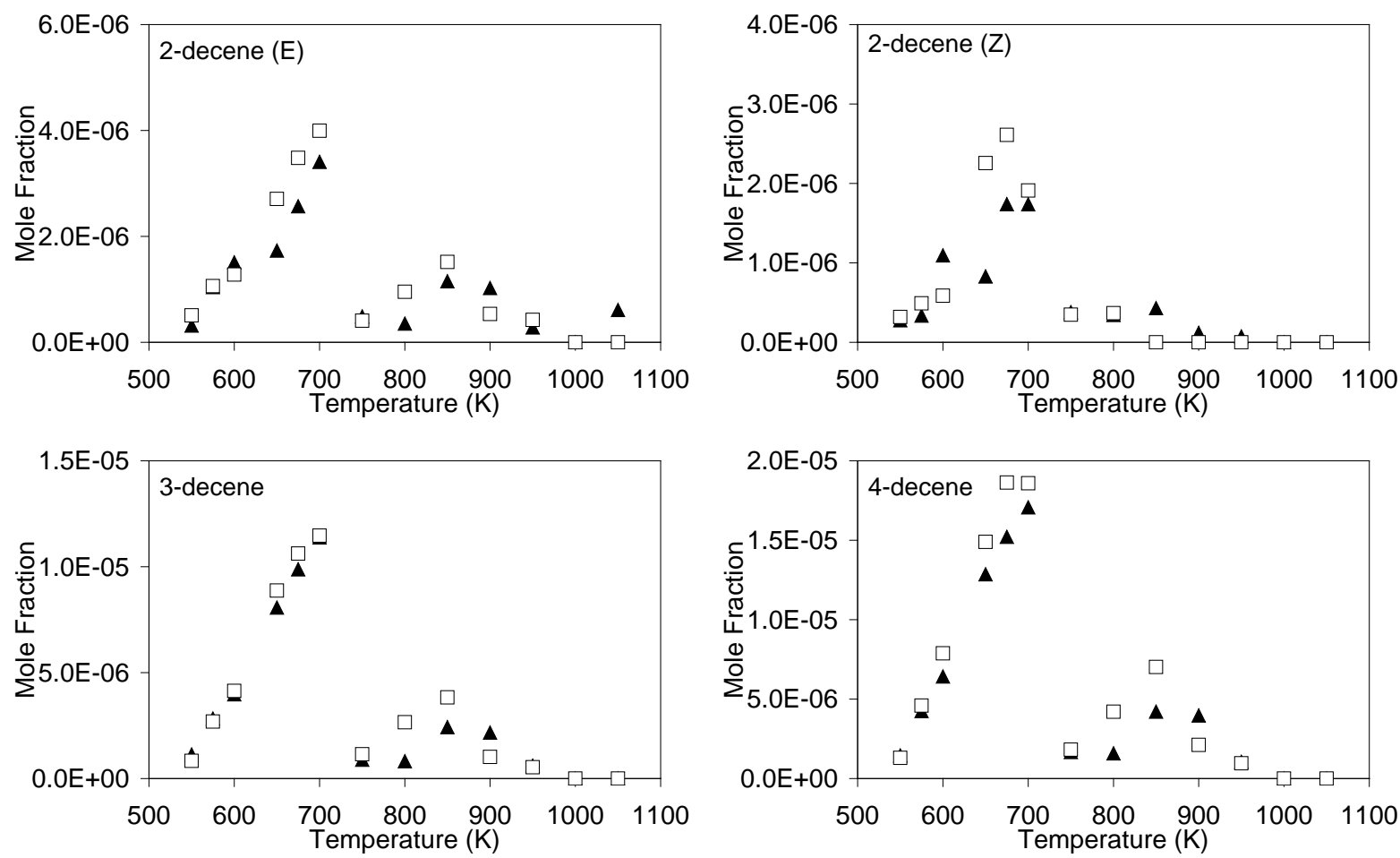

Fig. 14. Evolution and comparison of the mole fractions of isomers of decene formed by the reaction. $\square \mathrm{n}$-decane/n-hexadecane; up triangle, filled $\mathrm{n}$-decane/methyl palmitate.

Fig. 15 displays the distribution of 1-alkenes formed during the oxidation of both surrogate blends. In a general manner, the selectivity of a species decreases with the number of carbon atoms in the 1-alkenes. This is the case for 1-alkenes from the $\mathrm{n}$-decane/n-hexadecane blend. For the $\mathrm{n}$-decane/methyl palmitate, it seems that this statement is not valid. Selectivities of some species are much higher than expected. These particular species are 1-heptene, 1-octene and 1-tetradecene. We could not find any straightforward explanations for 1-heptene and 1-octene. As far as 1-tetradecene is concerned, the slightly higher selectivity can be explained by the fact that 1-tetradecene mainly comes from the decomposition of a $\mathrm{C}_{17} \mathrm{H}_{33} \mathrm{O}_{2}$ radical. There are two possibilities of $\mathrm{C}-\mathrm{C} \beta$-scission reactions for this radical (Fig. 16). The broken $\mathrm{C}-\mathrm{C}$ bond leading to 1-tetradecene is in the beta 
position of the carbonyl part of the ester group. This bond has an energy of $84.3 \mathrm{kcal} \mathrm{mol}^{-1}$ [35] which is slightly lower than a standard C-C bond in the alkyl chain (89.1 kcal mol ${ }^{-1}$ [35]). As a result, the activation energy of this reaction is likely lower than the activation energy of the reaction of $\beta$-scission of the other $\mathrm{C}-\mathrm{C}$ bonds in the chain, and reaction (1) in Fig. 16 is favored in comparison to reaction (2), while the two decomposition reactions have very similar rate constant in the case of other $\mathrm{C}_{17} \mathrm{H}_{33} \mathrm{O}_{2}$ radicals.

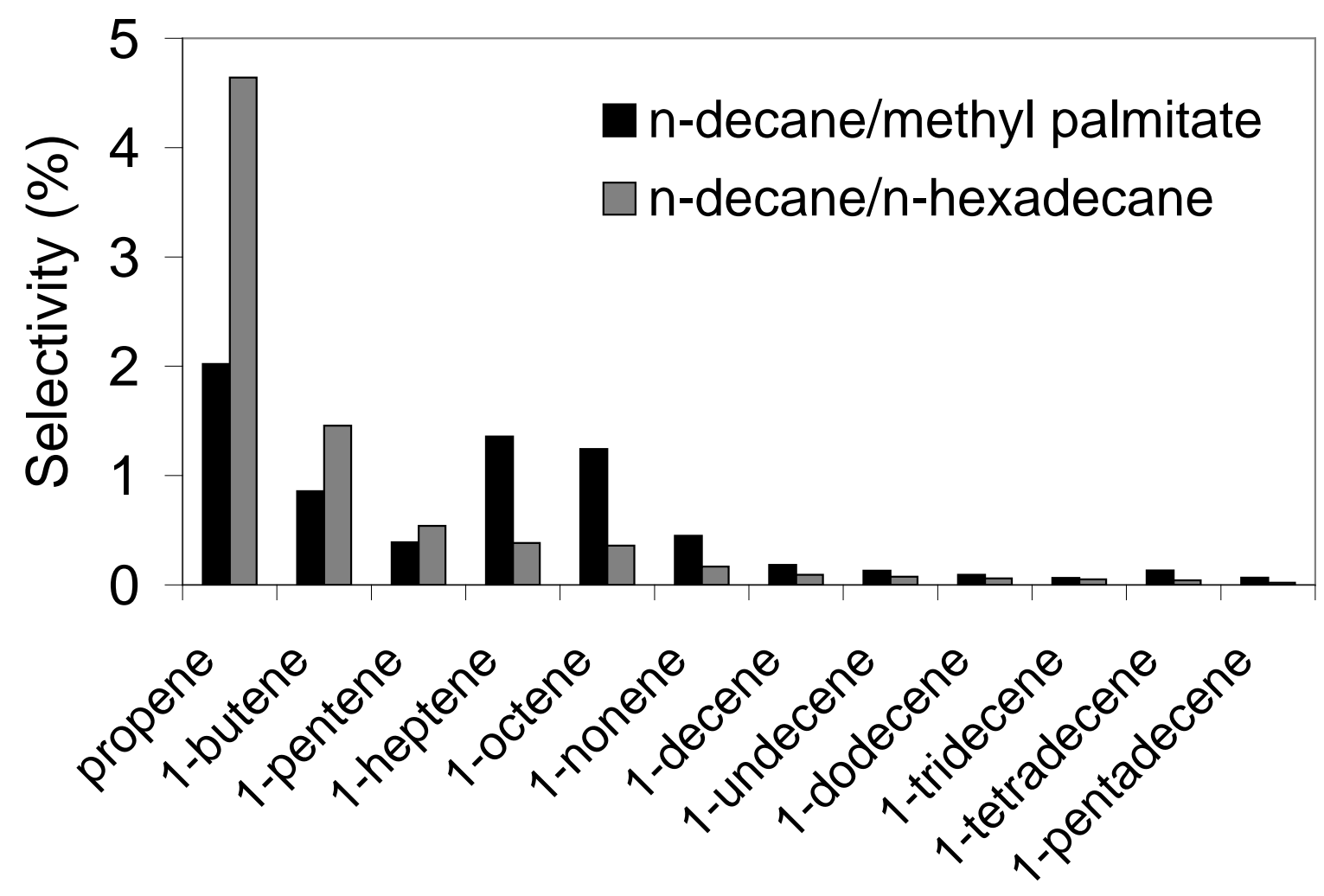

Fig. 15. Distribution of the 1-alkenes formed during the oxidation of the two surrogate blends $(T=$ $900 \mathrm{~K})$.<smiles>CCCCCCCCCCCC[CH]CCC(=O)OC</smiles><smiles>C=CCCCCCCCCCCCC</smiles><smiles>C=CCCC(=O)OC</smiles>

Fig. 16. Reactions of $\mathrm{C}-\mathrm{C} \beta$-scission decomposition of the $\mathrm{C}_{17} \mathrm{H}_{33} \mathrm{O}_{2}$ radical leading to 1-tetradecene. Channel (1) is favored by a lower activation energy due to the neighboring ester group. 

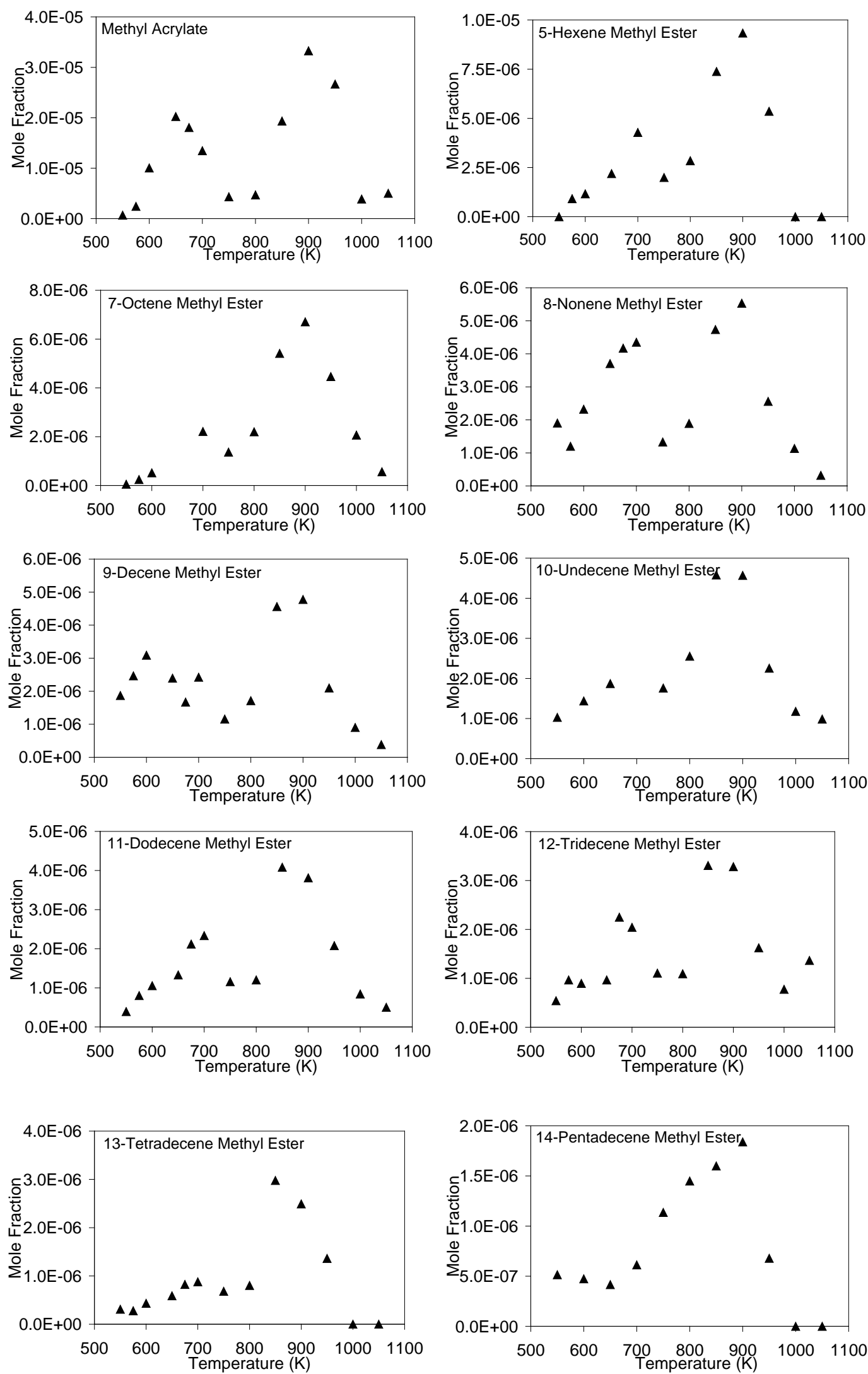

Fig. 17. Evolution of the mole fractions of unsaturated esters formed by the oxidation of the n-decane/methyl palmitate blend. 
Fig. 17 displays the mole fractions of unsaturated esters that have been observed during the study of the oxidation of the $\mathrm{n}$-decane/methyl palmitate blend. Because of very close retention times, peaks corresponding to 4-pentene and 6-heptene methyl esters were close to other peaks and we were not able to plot the mole fractions of these species as a function of the temperature. These species exhibit a NTC behavior and are formed in similar amount than 1-alkenes.

Fig. 18 displays the selectivity of unsaturated esters obtained from the oxidation of methyl palmitate. As expected, the selectivity of these unsaturated esters increases when the number of carbon atoms in the molecule goes down. The selectivity of 4-pentene methyl ester is not shown in Fig. 18 because this species could not be quantified as written earlier. But the selectivity of this particular species is likely lower than what could be expected, because its formation is in competition with the formation of 1-tetradecene, which is enhanced by the low energy of the $\mathrm{C}-\mathrm{C}$ bond in the beta position of the carbonyl group.

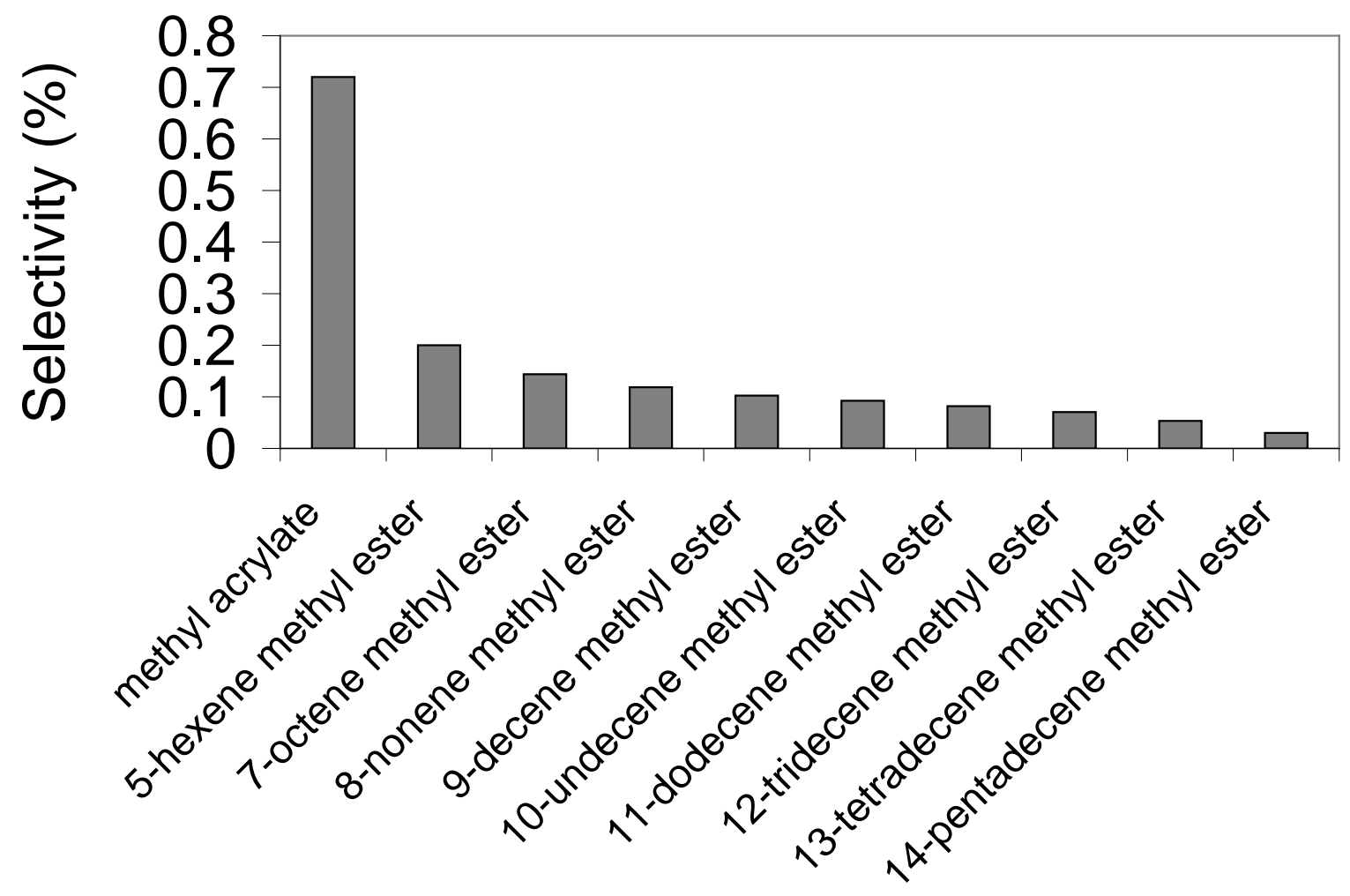

Fig. 18. Distribution of the unsaturated esters from the oxidation of methyl palmitate ( $T=900 \mathrm{~K})$.

Fig. 19 displays the evolution of the mole fraction as a function of the temperature for two cyclic ethers whose peaks were well defined. These two cyclic ethers are 2-methyl-5-undecyltetrahydrofuran (obtained from $\mathrm{n}$-hexadecane oxidation) and the cyclic ether $\mathrm{A}$ obtained from methyl palmitate (cyclic ether corresponding to the second peak $A$ on the chromatogram in Fig. 6). As retention times of most cyclic ethers were very close, Fig. 19 also displays the sum of the mole 
fractions of all isomers. It can be seen in Fig. 19 that cyclic ethers are only formed at low temperature and that they are not observed any more above $900 \mathrm{~K}$. According to the experimental results, the global mole fraction of cyclic ethers formed from n-hexadecane is about 1.5 times larger than the global mole fraction of cyclic ethers obtained from methyl palmitate.
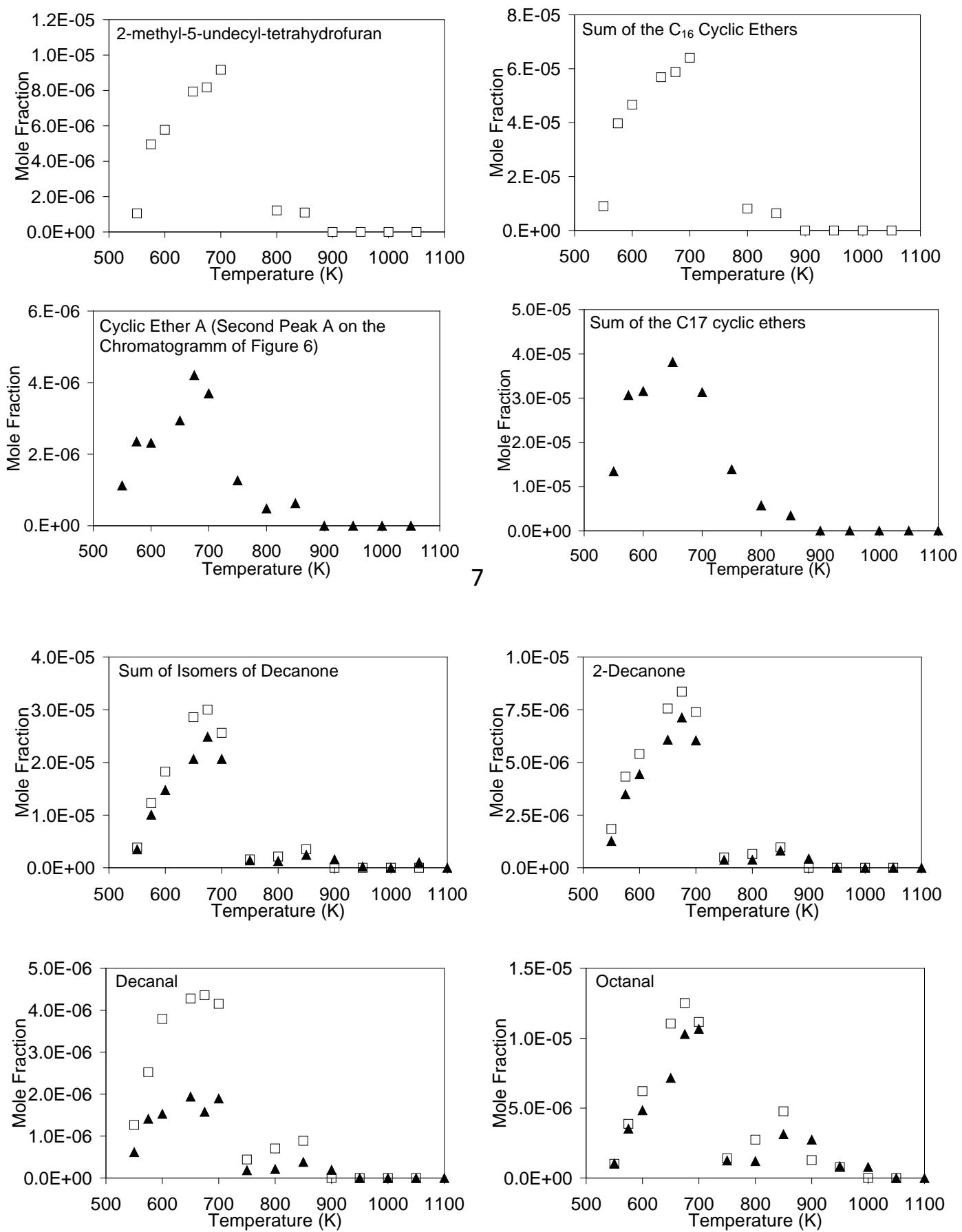

Fig. 19. Evolution of the mole fractions of large oxygenated compounds formed by the reaction. n-decane/n-hexadecane; $\Delta$ n-decane/methyl palmitate. 


\section{Conclusions}

The stoichiometric oxidation of a blend of $\mathrm{n}$-decane and methyl palmitate and of a blend of $\mathrm{n}$-decane and $\mathrm{n}$-hexadecane has been studied in a jet-stirred reactor over a wide range of temperatures (550$1100 \mathrm{~K}$ ), for a residence time of $1.5 \mathrm{~s}$, at quasi-atmospheric pressure and diluted in helium (hydrocarbon mole fraction 0.002). The experimental results that have been obtained during these studies have been compared in order to highlight similarities and differences in the oxidation of large methyl esters and normal alkanes. These species have very similar structures, the only difference between these two classes of compounds being the ester function that is attached to one end of the alkyl chain in methyl esters.

The comparison of the conversions of methyl palmitate and $\mathrm{n}$-hexadecane showed that these species have very similar reactivities and the same NTC behavior over the range of studied temperatures. Thus it seems to be reasonable to use large $n$-alkanes as surrogates for large methyl esters as far as the reactivity is concerned.

Due to the large number of carbon atoms in the reactant and to the conditions of the study (covering both low- and high-temperature regions), numerous products of the reaction have been detected during these experiments. The formation of most species has been observed in both experimental works because of the similarity of the two reactants. These common products are small oxygenated species (e.g., carbon oxides, methanol, acetaldehyde), small hydrocarbons (methane, acetylene, ethylene, ethane), and 1-olefins. The specific products that have been observed are:

- unsaturated esters with the double bond at the extremity of the chain, which can be considered like 1-olefins with an ester function at the other end of the chain;

- oxygenated compounds obtained at low temperature, such as cyclic ethers, also including an ester function.

These last species are very unusual and their identification by GC-MS required the deciphering of their mass spectra, as very few data were available in the databases. As far as cyclic ethers deriving from methyl palmitate are concerned, even the formation of the very particular 5-membered ring cyclic ether with the ester group included in the ring has been observed.

Species common to both surrogates exhibit very close profiles, showing similar evolution with temperature. Among these species, carbon monoxide was the only one for which no difference in the experimental mole fractions could be observed. Obtained mole fractions of carbon dioxide were larger with methyl palmitate than with $n$-hexadecane. For all other light oxygenated products, light hydrocarbon species, and large 1-alkenes, mole fractions were always larger for $\mathrm{n}$-hexadecane than for methyl palmitate; this was compensated by the formation of unsaturated esters, which was 
observed for methyl palmitate only. The mole fraction profiles of these last species were very similar to those of 1-olefins. Finally, the formation of oxygenated products such as cyclic ethers has been observed. These products had very similar mole fraction profiles for both surrogates and were formed at low temperatures only. According to the experimental results, the global amount of cyclic ethers was slightly larger with $\mathrm{n}$-hexadecane than with methyl palmitate. To sum up, the oxidation of methyl palmitate and $n$-hexadecane led to very similar amounts of oxygenated and hydrocarbon species.

Future work will consist in establishing the specific reactions, kinetic parameters, and thermochemistry that will allow the modeling of the oxidation of large saturated methyl esters and the inclusion of these new data in the EXGAS automatic generator of mechanisms [7] and [36]. Another future work in the area of the understanding of the kinetics of the oxidation of real biodiesel fuels will be the experimental study of the oxidation of a large unsaturated ester, in order to highlight the influence of double bonds on the kinetics of the reaction.

\section{Acknowledgments}

This work has been supported by ADEME-PREDIT in collaboration with IFP, TOTAL and PSA Peugeot Citroën through the program BIOKIN. The authors thank M. Crochet and Professor R. Minetti for their help in the mass spectra analysis.

\section{References}

[1] K. Bozbas, Renew. Sust. Energy Rev. 12 (2) (2008), pp. 542-552.

[2] A. Demirbas, Prog. Energy Combust. Sci. 31 (2005), pp. 466-487.

[3] M.S. Graboski and R.L. McCormick, Prog. Energy Combust. Sci. 24 (1998), pp. 125-164.

[4] , Avinash Kumar Agarwal, Prog. Energy Combust. Sci. 33 (2007), pp. 233-271.

[5] J. Van Gerpen, B. Shanks, R. Pruszko, D. Clements, G. Knothe, Biodiesel Production Technology, National Renewable Energy Laboratory Subcontractor Report NREL/SR-510-36244, 2004.

[6] F. Buda, R. Bounaceur, V. Warth, P.A. Glaude, R. Fournet and F. Battin-Leclerc, Combust. Flame 142 (1-2) (2005), pp. 170-186.

[7] J. Biet, M.H. Hakka, V. Warth, P.A. Glaude and F. Battin-Leclerc, Energy Fuel 22 (2008), pp. 22582269. 
[8] C.K. Westbrook, W.J. Pitz, O. Herbinet, H.J. Curran and E.J. Silke, Combust. Flame 156 (1) (2009), pp. 181-199.

[9] E. Ranzi, A. Frassoldati, S. Granata and T. Faravelli, Ind. Eng. Chem. Res. 44 (14) (2005), pp. 51705183.

[10] Y. Muharam and J. Warnatz, Phys. Chem. Chem. Phys. 9 (2007), pp. 4218-4229.

[11] B.I. Parsons and C.J. Danby, J. Chem. Soc. (1956), pp. 1795-1798.

[12] E.M. Fisher, W.J. Pitz, H.J. Curran and C.K. Westbrook, Proc. Combust. Inst. 28 (2000), pp. 15791586.

[13] W.K. Metcalfe, S. Dooley, H.J. Curran, J.M. Simmie, A.M. El-Nahas and M.V. Navarro, J. Phys. Chem. 111 (19) (2007), pp. 4001-4014.

[14] S. Gaï, M.J. Thomson, S.M. Sarathy, S.A. Syed, P. Dagaut, P. Diévart, A.J. Marchese and F.L. Dryer, Proc. Combust. Inst. 31 (1) (2007), pp. 305-311.

[15] S. Gaïl, S.M. Sarathy, M.J. Thomson, P. Diévart and P. Dagaut, Combust. Flame 155 (2008), pp. 635-650.

[16] A. Farooq, D.F. Davidson, R.K. Hanson, L.K. Huynh and A. Violi, Proc. Combust. Inst. 32 (2009), pp. 247-253.

[17] S.M. Walton, M.S. Wooldridge and C.K. Westbrook, Proc. Combust. Inst. 32 (2009), pp. 255-262.

[18] S. Dooley, H.J. Curran and J.M. Simmie, Combust. Flame 153 (2008), pp. 2-32.

[19] T. Vaughn, M. Hammill, M. Harris, A.J. Marchese, Ignition Delay of Bio-ester Fuel Droplets, SAE Technical Paper Series, 2006-01-3302.

[20] K. HadjAli, M. Crochet, G. Vanhove, M. Ribaucour and R. Minetti, Proc. Combust. Inst. 32 (2009), pp. 239-246.

[21] P. Dagaut, S. Gaïl and M. Sahasrabudhe, Proc. Combust. Inst. 31 (2) (2007), pp. 2955-2961.

[22] P. Dagaut and S. Gaïl, J. Phys. Chem. A 111 (2007), pp. 3992-4000.

[23] A. Ristori, P. Dagaut and M. Cathonnet, Combust. Flame 125 (3) (2001), pp. 1128-1137.

[24] J.R. Pedersen, Å. Ingemarsson and J.O. Olsson, Chemosphere 38 (11) (1999), pp. 2467-2474.

[25] J.P. Szybist, J. Song, M. Alam and A.L. Boehman, Fuel Process. Technol. 88 (7) (2007), pp. 679691.

[26] J.P. Szybist, A.L. Boehman, D.C. Haworth and H. Koga, Combust. Flame 149 (1-2) (2007), pp. $112-128$.

[27] O. Herbinet, W.J. Pitz and C.K. Westbrook, Combust. Flame 154 (2008), pp. 507-528. 
[28] K. Seshadri, T. Lu, O. Herbinet, S. Humer, U. Niemann, W.J. Pitz and C.K. Law, Proc. Combust. Inst. 32 (2009), pp. 1067-1074.

[29] O. Herbinet, P.M. Marquaire, F. Battin-Leclerc and R. Fournet, J. Anal. Appl. Pyrol. 78 (2006), pp. 419-429.

[30] D. Matras and J. Villermaux, Chem. Eng. Sci. 28 (1973), p. 129.

[31] R. David and D. Matras, Can. J. Chem. Eng. 53 (1975), p. 297.

[32] J. Tranchant, Manuel Pratique de Chromatographie en Phase Gazeuse, Masson, Paris, France, 1995, p. 470.

[33] P. Dagaut, M. Reuillon and M. Cathonnet, Combust. Sci. Technol. 103 (1994), pp. 349-359.

[34] E. de Hoffmann, J. Charette, V. Stroobant, Spectrométrie de Masse, Masson, Paris, France, 1994, p. 178.

[35] A.M. El-Nahas, M.V. Navarro, J.M. Simmie, J.W. Bozzelli, H.J. Curran, S. Dooley and W. Metcalfe, J. Phys. Chem. 111 (19) (2007), pp. 3727-3739.

[36] V. Warth, N. Stef, P.A. Glaude, F. Battin-Leclerc, G. Scacchi and G.M. Come, Combust. Flame 114 (1998), pp. 81-102. 